\title{
New triazepine carboxylate derivatives: correlation between corrosion inhibition property and chemical structure
}

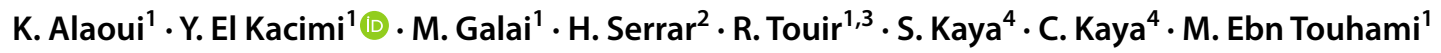

Received: 9 April 2019 / Accepted: 18 December 2019 / Published online: 4 January 2020

(c) The Author(s) 2020

\begin{abstract}
In this investigation, attempts have been made to study the corrosion inhibition properties of three new triazepine carboxylate compounds for mild steel in 1.0 M hydrochloric acid medium. The evaluation was carried out using mass loss, electrochemical impedance spectroscopy and polarization curves measurement. Impedance diagrams and Bode plots for uninhibited and inhibited systems were analyzed using Zview program. The fitted data observed trails in nearly the same pattern as the experimental results. It is showed that triazepine carboxylate compounds are very good inhibitors for mild steel corrosion in $1.0 \mathrm{M}$ hydrochloric acid medium which act as mixed-type inhibitors. So, the inhibition efficiency was increased with inhibitor concentration in the order $\mathrm{Cl}-\mathrm{Me}-\mathrm{CN}>\mathrm{Me}-\mathrm{CN}>\mathrm{Cl}-\mathrm{Me}-\mathrm{CO}_{2} \mathrm{Et}$ which depended on their molecular structures. Electrochemical impedance spectroscopy showed that all compounds act by the formation of a protective film at the metal surface. Surface analyses via SEM and Optical 3D profilometry were used to investigate the morphology of the steels before and after immersion in $1.0 \mathrm{M} \mathrm{HCl}$ solution containing inhibitors. The correspondence between inhibition property and molecular structure of the triazepine carboxylate compounds was investigated, using density functional theory (DFT). Experimental and DFT study was further supported by molecular dynamic simulations study.
\end{abstract}

Keywords Organic compounds - Triazepine carboxylate derivatives $\cdot$ Molecular dynamics $\cdot$ Ab initio calculations . Computer modeling and simulation $\cdot$ Corrosion inhibition $\cdot$ SEM $\cdot$ Optical 3D profilometry

\section{Introduction}

Hydrochloric acid pickling bath is used to remove the corrosion products from the metal working. Over-pickling can cause serious damage and physical properties of metals' structure can be easily done [1]. Thus, to control the risk and reduce the problem, several organic compounds are used as corrosion inhibitors [2-5].

K. Alaoui

khaoula.alaoui.elkacimi@gmail.com

Y. El Kacimi

elkacimiyounes@yahoo.fr

1 Laboratory of Materials Engineering and Environment: Application and Modeling, Faculty of Science, Ibn Tofail University, PO Box 133, 14000 Kenitra, Morocco

2 Laboratory of Organic, Organometallic Chemistry, Faculty of Science, Ibn Tofail University, Kenitra, Morocco

3 Centre Régional des métiers de l'éducation et de la formation, Madinat Al Irfane, BP 6210 Rabat, Morocco

4 Faculty of Science, Department of Chemistry, Cumhuriyet University, 58140 Sivas, Turkey
Currently, most of the effective inhibitors used have in their structure:

1. heteroatoms such as oxygen $(\mathrm{O})$, nitrogen $(\mathrm{N})$, phosphorus $(\mathrm{P})$, sulfur $(\mathrm{S})$;

2. aromatic component having multiple bonds leading to easier adsorption on the metal surface;

3. functional groups such as $=\mathrm{NH},-\mathrm{CHO},-\mathrm{C} \equiv \mathrm{N}$, $-\mathrm{N}=\mathrm{N}-\ldots$;

4. heterocyclic compounds such as imidazole, quinoline, quinoxaline, phenyltetrazole, etc. [6, 7].

In this case, we have established that triazepine carboxylate compounds can easily be protonated in acidic medium, thus getting adsorbed on the surface metal.

Recently, some workers have reviewed and provided a literature survey of triazepines compounds. The synthesis and characterization of a family of triazepine derivatives are of particular interest to the chemical and biological communities, and hence the chemistry and biochemistry of triazepine derivatives have been intensively investigated. Triazepine 
derivatives have diverse applications in wide-ranging fields, they have remarkable biological importance and medicinal and pharmaceutic potential. Some known derivatives of imidazotriazepines have shown activity as muscle relaxants, while others have antifungal, antidiabetic, antimicrobial, antiviral, anticancer, and analgesic properties [8-10].

Propelled by our interest in the synthesis of new efficient inhibitors, triazepines carboxylate substituted compounds $\left(\mathrm{Cl}-\mathrm{Me}-\mathrm{CO}_{2} \mathrm{Et}, \mathrm{Cl}-\mathrm{Me}-\mathrm{CN}\right.$ and $\left.\mathrm{Me}-\mathrm{CN}\right)$ have been developed, representing a promising way to improve the performance of corrosion inhibition in aggressive hydrochloric acid solution, owing to the existence of the cyano group.

The objective of the present paper is to study the inhibition efficiencies of triazepine carboxylate derivatives on mild steel corrosion in $1.0 \mathrm{M} \mathrm{HCl}$ and compare using weight loss measurements, electrochemical impedance spectroscopy, and potentiodynamic polarization analysis. Furthermore, quantum chemical calculations of density function theory (DFT) and molecular dynamics (MD) simulations were applied to theoretically determine the relationship between molecular structure and inhibition efficiency.

Surface morphology of the mild steel before and after exposing to $1.0 \mathrm{M} \mathrm{HCl}$ medium is also examined and discussed using scanning electron microscopy (SEM) and using 3D-profilometry images.

\section{Experimental details}

\section{Materials and weight loss measurements}

Mild steel specimens used have a rectangular form of $2.5 \mathrm{~cm} \times 2.0 \mathrm{~cm} \times 0.05 \mathrm{~cm}$ and have the following chemical composition (wt\%): C, 0.11; Si, 0.24; Mn, 0.47; Cr, 0.12; Mo, 0.02; Ni, 0.1; Al, 0.03; Cu, 0.14; Co, <0.012; $\mathrm{V},<0.003 ; \mathrm{W}, 0.06 ; \mathrm{Fe}$, balance. The samples' surface was polished with emery paper, rinsed with distilled water, degreased with ethanol, and dried in hot air. The immersion time for mass loss was $6 \mathrm{~h}$ at $298 \pm 2 \mathrm{~K}$. After immersion period, the samples were cleaned according to ASTM practice standard, and reweighed to $10^{-4} \mathrm{~g}$ for determining corrosion rate $[11,12]$. The hydrochloric acid pickling medium $(1.0 \mathrm{M} \mathrm{HCl})$ was prepared by dilution of analytical grade $37 \%$ of $\mathrm{HCl}$ with distilled water.

\section{Electrochemical cell}

The electrolysis cell used for potentiodynamic polarization measurement was a borosilicate glass cylinder closed by a cap with five apertures. The mild steel used as working electrode was pressure-fitted into a Polytetrafluoroethylene holder exposing only $1 \mathrm{~cm}^{2}$ of area to the $1.0 \mathrm{M}$ hydrochloric acid medium. Platinum and saturated calomel were used as counter and reference electrode, respectively. All potentials were measured against the previous electrode.

The potentiodynamic polarization curves were recorded by changing the electrode potential automatically from negative values to positive values versus $E_{\mathrm{OCP}}$ using a potentiostat/galvanostat type PGZ 100, at a scan rate of $1 \mathrm{mV} / \mathrm{s}$ after $30 \mathrm{~min}$ of immersion time until reaching steady state. The test solution was thermostatically controlled at $298 \pm 2 \mathrm{~K}$ in air atmosphere without bubbling. To evaluate corrosion kinetic parameters, a fitting by Stern-Geary equation was used. To do so, the overall current density values, $i$, were considered as the sum of two contributions, anodic and cathodic current $\left(i_{\mathrm{a}}\right)$ and $\left(i_{\mathrm{c}}\right)$, respectively. For the potential domain not too far from the open circuit potential, it may be considered that both processes followed the Tafel law [13]. Thus, it can be derived from Eq. (1):

$i=i_{\mathrm{a}}+i_{\mathrm{c}}=i_{\text {corr }}\left\{\exp \left[b_{\mathrm{a}} \times\left(E-E_{\text {corr }}\right)\right]-\exp \left[b_{\mathrm{c}} \times\left(E-E_{\text {corr }}\right)\right]\right\}$

where $i_{\text {corr }}$ is the corrosion current density $\left(\mathrm{A} \mathrm{cm}^{-2}\right), b_{\mathrm{a}}$ and $b_{\mathrm{c}}$ are the Tafel constants of anodic and cathodic reactions $\left(\mathrm{V}^{-1}\right)$, respectively. These constants are linked to the Tafel slopes $\beta(\mathrm{V} / \mathrm{dec})$ in usual logarithmic scale given by Eq. (2):

$\beta=\frac{\ln 10}{b}=\frac{2.303}{b}$

The corrosion inhibition efficiency is evaluated from the corrosion current densities values using the relationship (3):

$\eta_{\mathrm{pp}}(\%)=\left(\frac{i_{\text {corr }}-i_{\text {corr(inh })}}{i_{\text {corr }}}\right) \times 100$

The surface coverage values $(\theta)$ have been obtained from polarization curves for various concentrations of inhibitor using the following Eq. (4) [14]:

$\theta_{\mathrm{PP}}=1-\left(i_{\text {corr(inh) }} / i_{\text {corr }}\right)$

where $\left(i_{\text {corr }}\right)$ and $\left(i_{\text {corr(inh })}\right)$ are the corrosion current densities values without and with inhibitor, respectively.

The electrochemical impedance spectroscopy (EIS) tests were carried out using potentiostat/galvanostat type PGZ 100 and controlled by software model (Voltamaster 4) under static conditions. The same condition and equipment as above were used. The EIS experiments were conducted in the frequency range with high limit of $100 \mathrm{kHz}$ and different low limit $0.1 \mathrm{~Hz}$ at open circuit potential $\left(E_{\mathrm{OCP}}\right)$, with 10 points per decade, at the rest potential, after $30 \mathrm{~min}$ of acid immersion, by applying $10 \mathrm{mV}$ ac voltage peak-topeak. Nyquist plots were made from these experiments. The impedance data were analyzed and fitted with the simulation ZView 2.80, equivalent circuit software. 
To ensure reproducibility, all experiments were repeated three times where the evaluated inaccuracy did not exceed $10 \%$.

The inhibition efficiencies $\eta_{\text {EIS }} \%$ were calculated from Nyquist plots by Eq. (5):

$\eta_{\mathrm{EIS}}(\%)=\left(\frac{R_{\mathrm{ct}(\mathrm{inh})}-R_{\mathrm{ct}}}{R_{\mathrm{ct}}}\right) \times 100$

where $R_{\mathrm{ct}}$ and $R_{\mathrm{ct}(\mathrm{inh})}$ are the ac transfer resistance of mild steel electrode in the uninhibited and inhibited solutions, respectively.

\section{Computational details}

The molecular dynamics (MD) simulations were performed using Material Studio. Fe (110) surface was chosen for the simulation study. COMPASS force field was used to optimize the structures of all components of the system. The most stable plane of crystalline metals is the one with densely packed structure, and it is commonly used in molecular dynamics simulations to represent the corroding substrate metal $[15$, 16]. The simulations were performed in a simulation box of dimensions $(3.44 \mathrm{~nm} \times 4.05 \mathrm{~nm} \times 5.34 \mathrm{~nm})$. The molecular dynamics simulations were carried out with periodic boundary conditions to model a representative part of the interface devoid of any arbitrary boundary effects. First, the surface of pure $\mathrm{Fe}$ crystal was cleaved, and relaxed by minimizing its energy by means of molecular mechanics. Next, the surface of cleaved plane $\mathrm{Fe}$ (110) was enlarged to a super cell of an appropriate size, and then a vacuum slab with zero thickness was built above these surfaces. Since corrosion inhibition in aqueous solution is an electrochemistry process, the use of water molecules and different ions is essential. The effect of chemical species involved in the adsorption system was taken into consideration, thus the system in the molecular dynamics simulations incorporated $250 \mathrm{H}_{2} \mathrm{O}, 5 \mathrm{H}^{+}, 5 \mathrm{Cl}^{-}$and one inhibitor molecule in each case [17]. Finally, the most stable orientation of inhibitor molecules on metal surface was searched by Monte Carlo search simulations. The molecular dynamics simulations were performed at $298 \mathrm{~K}$ (controlled by the Andersen thermostat) using a canonical ensemble (NVT) with a time step of $1.0 \mathrm{fs}$, and a simulation time of 500 ps. For the whole simulation procedure, the COMPASS (Condensed-phase Optimized Molecular Potentials for Atomistic Simulation Studies) force field [18] was used, because it allows accurate and simultaneous prediction of structural, conformational, vibrational, and thermophysical properties for a broad range of chemical species, including organic molecules, metals, metal oxides, and metal halides [19].

All computations have been carried out with the Gaussian package program. For calculations, the hybrid exchange correlation functional (B3LYP) method was a turning point for DFT methods and polarized basis sets such as 6-311G $(d, p), 6-311++\mathrm{G}(d, p), 6-311 \mathrm{G}++(2 d, 2 p)$ were preferred. A full optimization was performed up to a higher basis set denoted by $6-31 \mathrm{G}++(d, p)$, because this basis set gives more accurate results in terms of the determination of geometries and electronic properties for a wide range of organic compounds. These calculations were performed in the gas phase, hydrochloric acid solution and for the protonated forms.

So, Parr and al. defined derivatives of the electronic energy $(E)$ with respect to number of electrons $(N)$ at a constant external potential $v(r)$, chemical reactivity indices such as chemical potential $(\mu)$, electronegativity $(\chi)$ and chemical hardness $(\eta)$. According to them, these above-mentioned parameters are given as [20,21]:

$\chi=-\mu=-\left(\frac{\partial E}{\partial N}\right)_{v(r)}$

$\eta=\frac{1}{2}\left(\frac{\partial \mu}{\partial N}\right)_{v(r)}=\frac{1}{2}\left(\frac{\partial^{2} E}{\partial N^{2}}\right)_{\nu(r)}$

In addition, the chemical hardness $(\eta)$, chemical potential $(\mu)$ and electronegativity $(\chi)$ were calculated using the following equations [22]:

$\chi=-\mu=\frac{I+A}{2}$

$\eta=\frac{I-A}{2}$

where $I$ and $A$ are the first vertical ionization energy and electron affinity values of any chemical system, respectively.

However, the negative of the highest occupied molecular orbital energy $\left(E_{\mathrm{HOMO}}\right)$ and the negative of the lowest unoccupied molecular orbital energy $\left(E_{\text {LUMO }}\right)$ correspond to ionization energy and electron affinity which were calculated using the following equations [23]:

$\mu=-\chi=\frac{E_{\mathrm{LUMO}}+E_{\mathrm{HOMO}}}{2}$

$\eta=\frac{E_{\mathrm{LUMO}}-E_{\mathrm{HOMO}}}{2}$

Global softness is defined as the inverse of global hardness and is given as [24, 25]:

$S=\frac{1}{\eta}=2\left(\frac{\partial N}{\partial \mu}\right)_{v(r)}$

Electrophilicity [26] that indicates the tendency of the inhibitor molecule to accept electrons is an important parameter in terms of the comparison of corrosion inhibition 
efficiencies of molecules. This parameter is defined via the following equation [27]:

$\omega=\frac{\mu^{2}}{2 \eta}=\frac{\chi^{2}}{2 \eta}$

\section{Surface morphology analysis}

3D optical profiler images and scanning electron microscope (SEM) were used to examine the polished surface of mild steel samples before and after immersion in $1.0 \mathrm{M} \mathrm{HCl}$ (blank solution), and the inhibited solution with $10^{-3} \mathrm{M}$ of inhibitor at $298 \mathrm{~K}$.

\section{Experimental result}

\section{Synthesis and characterization of inhibitors}

The newly synthesized triazepine carboxylate derivatives studied were synthesized according to the procedure below (Method for the synthesis) and confirmed by spectral studies such as FT-IR, ${ }^{1} \mathrm{H}$ NMR, ${ }^{13} \mathrm{CNHMR}$ and MS. Their characterization data and also, the International Union of Pure and Applied Chemistry (IUPAC) name, molecular structure and molecular formula are recorded in Table 1.

\section{Method for the synthesis}

A solution of epoxide $\underline{\mathbf{2}}(1 \mathrm{mmol})$ in acetonitrile $(20 \mathrm{~mL})$ was added to 1,6 -diaminopyridone $\mathbf{1}(1,2 \mathrm{mmol})$. The mixture was then refluxed for $36 \mathrm{~h}$. After that, the solvent was removed under reduced pressure and the crude product was treated with a mixture of ether/petroleum ether. The desired pyrido[1,2b] [1, 2, 4] triazepine-2,7-dione derivatives $\underline{\mathbf{3}}$ a-I were precipitated and then were recrystallized using the proper solvent (Scheme 1) [10].

\section{Corrosion of mild steel in $1.0 \mathrm{M} \mathrm{HCl}$ and its inhibition}

\section{Weight loss measurements}

The effect of different concentrations of triazepine carboxylate derivatives on mild steel corrosion in $1.0 \mathrm{M} \mathrm{HCl}$ was studied using the gravimetric method. For every concentration, the mean value of the corrosion rate $\omega_{\text {corr }}\left(\mathrm{mg} \mathrm{cm}^{-2}\right.$ $\mathrm{h}^{-1}$ ) was determined and the inhibition efficiency, $\eta_{\omega} \%$, was calculated using Eq. (14):

$\eta_{\omega} \%=\frac{\omega_{\text {corr }}^{0}-\omega_{\text {corr }}}{\omega_{\text {corr }}^{0}} \times 100$
The surface coverage values $(\theta)$ have been obtained from weight loss measurements using the following equation:

$\theta_{\omega}=1-\frac{\omega_{\text {corr }}}{\omega_{\text {corr }}^{0}}$

Inhibition coefficient $(\gamma)$ was calculated using Eq. (16):

$\gamma=\frac{\omega_{\text {corr }}^{0}}{\omega_{\text {corr }}}$

where $\omega_{\text {corr }}^{0}$ and $\omega_{\text {corr }}$ are the corrosion rate in uninhibited and inhibited solutions, respectively.

The obtained results are given in Table 2 .

It is showed that the inhibition efficiencies increase with concentrations and reach a maximum value of $93.2 \%, 88.9 \%$ and $87.4 \%$ at $10^{-3} \mathrm{M}$ of Cl-Me-Et, 2Cl-Me and 2Cl-Et, respectively. However, if the concentration of the inhibitor is increased beyond certain (optimum) value, the inhibitor molecules adsorb perpendicularly onto the metallic surface due to electrostatic repulsion between the molecules at higher concentration. Therefore, after the optimum concentration of the inhibitor, the inhibition performance does not change significantly. On the other hand, the effectiveness of organic compounds mainly depends on their size and their active centers [28]. It is noted also that the inhibition efficiency follows the order: $\mathrm{Cl}-\mathrm{Me}-\mathrm{CN} \approx \mathrm{Me}-\mathrm{CN}>\mathrm{Cl}-\mathrm{Me}-\mathrm{CO}_{2} \mathrm{Et}$. It is revealed that the inhibition coefficient reaches a maximum value of $18.82,16.78$ and 8.17 at $10^{-3} \mathrm{M}$ of $\mathrm{Cl}-\mathrm{Me}-\mathrm{CN}$, $\mathrm{Me}-\mathrm{CN}$ and $\mathrm{Cl}-\mathrm{Me}-\mathrm{CO}_{2} \mathrm{Et}$ respectively. This order can be explained by the rise of the effective electron density at the functional group of inhibitors [28, 29]. So, the compounds have aromatic or heterocyclic ring, the effective electron density at the functional group can be changed by the introduction of different substituents in the ring causing variations in their molecular structure leading to a change in their corrosion inhibition efficiencies. The high inhibition efficiency of $\mathrm{Cl}-\mathrm{Me}-\mathrm{CN}$ and $\mathrm{Me}-\mathrm{CN}$ compared to $\mathrm{Cl}-\mathrm{Me}-\mathrm{CO}_{2} \mathrm{Et}$ is due to the presence of nitrile $(-\mathrm{C} \equiv \mathrm{N})$ cyano group. In addition, high-efficiency protective film for $\mathrm{Cl}-\mathrm{Me}-\mathrm{CN}$ compared to $\mathrm{Me}-\mathrm{CN}$ is due to the presence of methyl group $-(\mathrm{Cl})$ group. The nucleophilic (electron releasing) character of $-(\mathrm{Cl})$ is higher than the electrophonic (electron withdrawing).

\section{Potentiodynamic polarization curves}

The potentiodynamic polarization behavior of mild steel in 1.0 M HCl without and with different concentrations of all substituted triazepine carboxylate compounds is shown in Fig. 1a-c. Their electrochemical data are given in Table 3 . It is known that the electrochemical reactions of the mild steel in acidic medium, in the absence of inhibitors, are the 


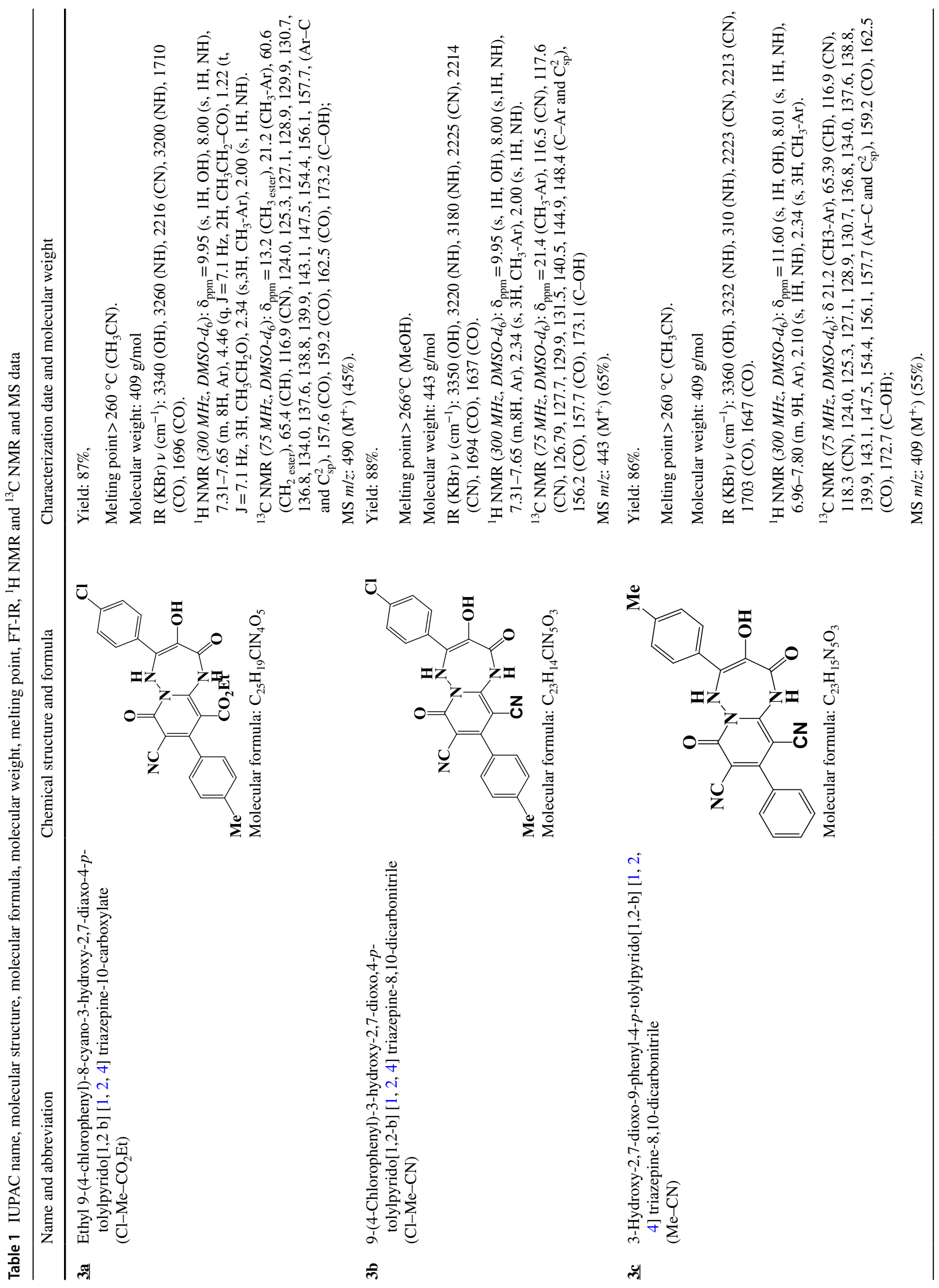


Scheme 1 Synthesis reaction of the pyridotriazepines $\underline{\mathbf{3}}$ a-c<smiles>[R]c1ccc(-c2c([X])c(N)n(N)c(=O)c2C#N)cc1</smiles>

$\underline{1}$

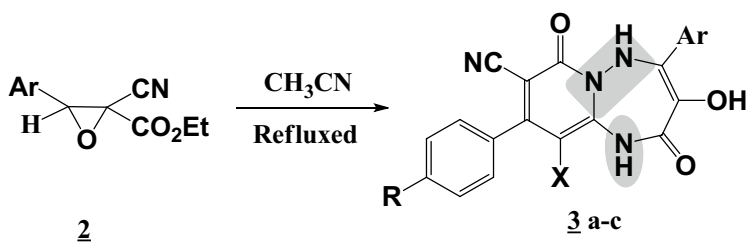

3a) R: $\mathrm{Me}, \mathrm{X}=\mathrm{CO}_{2} \mathrm{Et}$, $\mathrm{Ar}$ : $\mathrm{C}_{6} \mathrm{H}_{4} \mathrm{Cl}$

3b) R: $\mathrm{Me}, \mathrm{X}=\mathrm{CN} \quad, \mathrm{Ar}: \mathrm{C}_{6} \mathrm{H}_{4} \mathrm{Cl}$ 3c) $\mathrm{R}: \mathrm{H}, \mathrm{X}=\mathrm{CN} \quad, \mathrm{Ar}: \mathrm{C}_{6} \mathrm{H}_{4} \mathrm{CH}_{3}$
Table 2 Weight loss data of mild steel in $1.0 \mathrm{M} \mathrm{HCl}$ without and with different concentrations of substituted triazepine carboxylate derivatives at $298 \pm 2 \mathrm{~K}$ after $6 \mathrm{~h}$ of immersion

\begin{tabular}{|c|c|c|c|c|}
\hline Conc. (M) & $\begin{array}{l}\omega_{\text {corr }}\left(\mathrm{mg} \mathrm{cm}^{-2}\right. \\
\left.\mathrm{h}^{-1}\right)\end{array}$ & $\eta_{\omega}(\%)$ & $\theta_{\omega}$ & $\gamma$ \\
\hline \multicolumn{5}{|c|}{ Blank solution $(1.0 \mathrm{M} \mathrm{HCl} /$ mild steel $)$} \\
\hline 0 & 1.90 & - & - & - \\
\hline \multicolumn{5}{|c|}{$\mathrm{Cl}-\mathrm{Me}-\mathrm{CO}_{2} \mathrm{Et} / 1.0 \mathrm{M} \mathrm{HCl} / \mathrm{mild}$ steel } \\
\hline $10^{-6}$ & 0.36 & 79.0 & 0.790 & 4.77 \\
\hline $10^{-5}$ & 0.31 & 79.5 & 0.795 & 4.88 \\
\hline $10^{-4}$ & 0.28 & 84.2 & 0.842 & 6.35 \\
\hline $10^{-3}$ & 0.20 & 87.8 & 0.878 & 8.17 \\
\hline \multicolumn{5}{|c|}{$\mathrm{Cl}-\mathrm{Me}-\mathrm{CN} / 1.0 \mathrm{M} \mathrm{HCl} / \mathrm{mild}$ steel } \\
\hline $10^{-6}$ & 0.90 & 10.2 & 0.102 & 1.11 \\
\hline $10^{-5}$ & 0.32 & 82.9 & 0.829 & 5.85 \\
\hline $10^{-4}$ & 0.19 & 89.5 & 0.895 & 9.55 \\
\hline $10^{-3}$ & 0.12 & 94.7 & 0.947 & 18.82 \\
\hline \multicolumn{5}{|c|}{$\mathrm{Me}-\mathrm{CN} / 1.0 \mathrm{M} \mathrm{HCl} / \mathrm{mild}$ steel } \\
\hline $10^{-6}$ & 0.25 & 81.7 & 0.817 & 5.46 \\
\hline $10^{-5}$ & 0.21 & 87.0 & 0.870 & 7.72 \\
\hline $10^{-4}$ & 0.14 & 92.9 & 0.929 & 13.99 \\
\hline $10^{-3}$ & 0.11 & 94.0 & 0.940 & 16.78 \\
\hline
\end{tabular}

anodic dissolution of iron and cathodic of proton reduction reactions:

At the anode electrode:

$\mathrm{Fe} \leftrightarrow \mathrm{Fe}^{2+}+2 \mathrm{e}^{-}$

And while iron is corroding, the rate of reaction is usually controlled by the cathodic process (hydrogen):

$2 \mathrm{H}^{+}+2 \mathrm{e}^{-} \leftrightarrow \mathrm{H}_{2}$

It can be shown that the triazepine carboxylate derivatives addition hinders the acid attack on mild steel. It is noted also that the inhibitors' addition shifts slightly the $E_{\text {corr }}$ to the anodic directions. According to Riggs [4], if the displacement in:

1. $E$ is $>85 \mathrm{mV} / E_{\text {corr }}$, the inhibitor can be classified as a cathodic or anodic type;

2. $E$ is $<85 \mathrm{mV} / E_{\text {corr }}$, it can be classified as a mixed type.
In our study, this displacement in the case of all products was more than $85 \mathrm{mV} / E_{\text {corr }}$ which indicated that all these compounds were classified as the mixed-type inhibitors.

In addition, it is clear that the current density decreases with concentrations indicating that these compounds are adsorbed on the metal surface.

However, it is observed that these inhibitors have an effect on both the cathodic and anodic slopes $\left(\beta_{\mathrm{c}}\right.$ and $\left.\beta_{\mathrm{a}}\right)$ signifying a modification of cathodic hydrogen evolution (Eq. (17)) mechanism as well as anodic dissolution of iron (Eq. (18)). In addition, the change in $\beta_{\mathrm{a}}$ may be ascribed to changes in the charge transfer coefficient $\alpha_{\mathrm{a}}$ for anodic dissolution of ' $\mathrm{Fe}$ ' by virtue of the presence of an additional energy barrier due to the presence of adsorbed inhibitors [30].

Finally, it is seen also that the $\eta_{\mathrm{PP}}$ followed the order: $\mathrm{Cl}-\mathrm{Me}-\mathrm{CN}>\mathrm{Me}-\mathrm{CN}>\mathrm{Cl}-\mathrm{Me}-\mathrm{CO}_{2}$ Et such as found by the weight loss measurements.

Besides, the recorded polarization curves in the presence of triazepine carboxylate compounds (Fig. 1a-c) are characterized by the presence of anodic breakdown potential, $E_{\mathrm{b}}$. This is the potential at which sudden rise in current density takes place. As a result, the surface film is shifted from a stable to unstable state. As the concentration of inhibitor increased, $E_{\mathrm{b}}$ shifted to a noble direction. The noble shift of $E_{\mathrm{b}}$ with concentrations reflected the increased inhibitors adsorption on the metallic surface. This shift in $E_{\mathrm{b}}$ with the studied triazepine carboxylate concentrations reflected the formation of anodic protective film on the electrode surface $[31,32]$. However, for a potential higher than $-300 \mathrm{mV}_{\mathrm{SCE}}$ versus $E_{\text {corr }}$ the presence of triazepine carboxylate compounds did not change the current/potential characteristics. This potential can be defined as the desorption potential.

The phenomenon may be due to the obvious metal dissolution, which led to desorption of the inhibitor molecule from the electrode surface, in this case the desorption rate of the inhibitors is higher than its adsorption rate, so the corrosion current obviously increased with rising potential [33].

The presence of nitrile $(-\mathrm{C} \equiv \mathrm{N})$ cyano group and $-(\mathrm{Cl})$ group on 4-(4-chlorophenyl)-3-hydroxy-2,7-dioxo-9-( $p$ tolyl)-1,2,5,7-tetrahydropyrido[1,2-b] [1, 2, 4] triazepine8,10-dicarbonitrile $(\mathrm{Cl}-\mathrm{Me}-\mathrm{CN})$ can produce protonated species in $\mathrm{HCl}$ by the reaction of the amino group with $\mathrm{HCl}$. 

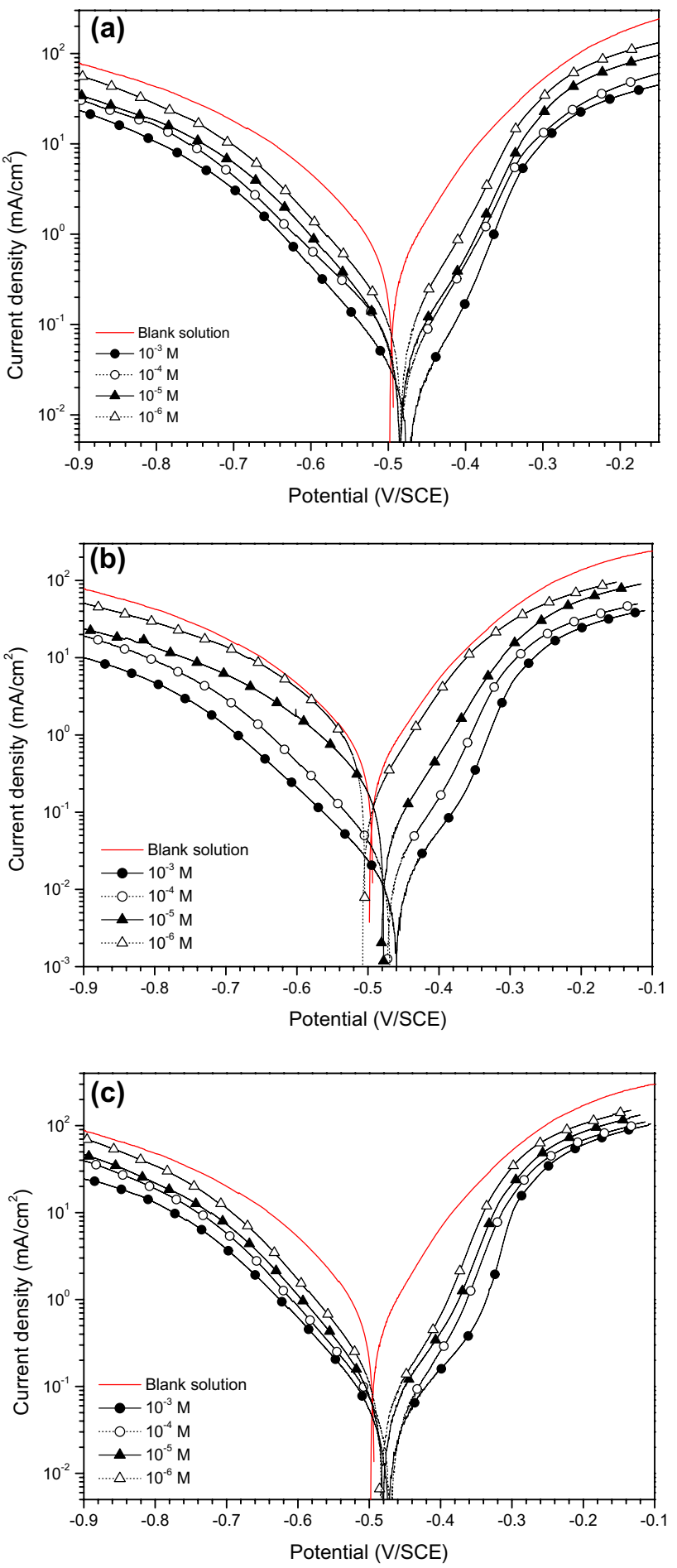

Fig. 1 Potentiodynamic polarization curves for mild steel in $1.0 \mathrm{M}$ $\mathrm{HCl}$ in the absence and presence of various concentrations of $\mathbf{a ~ C l -}$ $\mathrm{Me}-\mathrm{CO}_{2} \mathrm{Et}$, b $\mathrm{Cl}-\mathrm{Me}-\mathrm{CN}$ and $\mathbf{c} \mathrm{Me}-\mathrm{CN}$

On the other hand, according to Trethewey and Chamberlain [34], at a high concentration, anions present in the solution may either become inhibitive or act in such a way as to plug any pores in a passive film. The mechanism of the anodic dissolution of mild steel in $\mathrm{HCl}$ is [35]:
$\mathrm{Fe}+\mathrm{Cl}^{-} \leftrightarrow\left[\mathrm{FeCl}^{-}\right]_{\mathrm{ads}}$

$\left[\mathrm{FeCl}^{-}\right]_{\mathrm{ads}} \leftrightarrow[\mathrm{FeCl}]_{\mathrm{ads}}+\mathrm{e}^{-}$

$[\mathrm{FeCl}]_{\mathrm{ads}} \leftrightarrow\left[\mathrm{FeCl}^{+}\right]_{\mathrm{ads}}+\mathrm{e}^{-}$

$\left[\mathrm{FeCl}^{+}\right]_{\text {ads }} \leftrightarrow \mathrm{Fe}^{2+}+\mathrm{Cl}^{-}$

The mechanism for cathodic hydrogen evolution is [36]:

$\mathrm{Fe}+\mathrm{H}^{+} \leftrightarrow\left[\mathrm{FeH}^{+}\right]_{\mathrm{ads}}$

$\left[\mathrm{FeH}^{+}\right]_{\mathrm{ads}}+\mathrm{e}^{-} \leftrightarrow[\mathrm{FeH}]_{\mathrm{ads}}$

$[\mathrm{FeH}]_{\mathrm{ads}}+\mathrm{H}^{+}+\mathrm{e}^{-} \leftrightarrow \mathrm{Fe}+\mathrm{H}_{2}$

In this case, it would be difficult for the protonated species of the triazepine carboxylate derivatives molecules to approach the positively charged mild steel surface because of electrostatic repulsion. In the presence of $\mathrm{Cl}^{-}$ions, the anions are adsorbed onto the mild steel surface which allows the protonated species of the triazepine derivatives molecules to easily approach the surface.

\section{Electrochemical impedance spectroscopy}

Figure 2a-c show typical Nyquist plots for mild steel in 1.0 $\mathrm{M} \mathrm{HCl}$ in the absence and presence of different concentrations of $\mathrm{Cl}-\mathrm{Et}-\mathrm{CN}, \mathrm{Me}-\mathrm{CN}$ and $\mathrm{Cl}-\mathrm{Me}-\mathrm{CO}_{2} \mathrm{Et}$ at the $\mathrm{E}_{\mathrm{OCP}}$. It is noted that the impedance response was composed by one capacitive loop where its diameter significantly changed after all inhibitors' addition and the maximum was obtained at $10^{-3} \mathrm{M}$ of triazepine carboxylate compounds. This capacitive loop can be attributed to the charge transfer reaction.

The used equivalent electric circuit with one time constant was presented in Fig. 3. This circuit contains the parameters which can be named as: $R_{\mathrm{s}}$ is the solution resistance, $R_{\mathrm{ct}}$ is the charge transfer resistance and $\mathrm{CPE}_{\mathrm{dl}}$ is the constant phase element of the double layer such as indicated above.

An excellent fit was obtained for all experimental data. For the description of depressed semicircles with their centers below the real axis, a constant phase element (CPE) was used and expressed as [37]:

$Z_{\mathrm{CPE}}=\frac{1}{A(i \omega)^{n}}$

where $A\left(\Omega^{-1} \mathrm{~s}^{\mathrm{n}} \mathrm{cm}^{-2}\right)$ is the magnitude of the CPE, $\omega$ $\left(\mathrm{rad} \mathrm{s}^{-1}\right)$ is the sine wave modulation angular frequency, $i^{2}=-1$ is the imaginary number and $n$ is an empirical 
Table 3 Electrochemical parameters for mild steel in $1.0 \mathrm{M} \mathrm{HCl}$ at various concentrations of inhibitors

\begin{tabular}{|c|c|c|c|c|c|c|}
\hline Conc./M & $\begin{array}{l}E_{\text {corr }} / \mathrm{mV} \\
\text { versus SCE }\end{array}$ & $i_{\text {corr }} / \mu \mathrm{A} \mathrm{cm}^{-2}$ & $\beta_{\mathrm{c}}\left(\mathrm{mV} \mathrm{dec}{ }^{-1}\right)$ & $\beta_{\mathrm{a}}\left(\mathrm{mV} \mathrm{dec}{ }^{-1}\right)$ & $\eta_{\mathrm{pp}} / \%$ & $\theta_{\mathrm{PP}}$ \\
\hline \multicolumn{7}{|c|}{ Blank solution (1.0 M HCl without inhibitors) } \\
\hline- & -498 & 983 & -140 & 150 & - & - \\
\hline \multicolumn{7}{|c|}{$\mathrm{Cl}-\mathrm{Me}-\mathrm{CO}_{2} \mathrm{Et} / 1.0 \mathrm{M} \mathrm{HCl} / \mathrm{mild}$ steel } \\
\hline $10^{-6}$ & -480 & 182 & -113 & 70 & 81.5 & 0.815 \\
\hline $10^{-5}$ & -481 & 165 & -112 & 63 & 83.2 & 0.832 \\
\hline $10^{-4}$ & -482 & 127 & -119 & 70 & 87.1 & 0.871 \\
\hline $10^{-3}$ & -470 & 73 & -107 & 60 & 92.6 & 0.926 \\
\hline \multicolumn{7}{|c|}{$\mathrm{Cl}-\mathrm{Me}-\mathrm{CN} / 1.0 \mathrm{M} \mathrm{HCl} / \mathrm{mild}$ steel } \\
\hline $10^{-6}$ & -502 & 912 & -182 & 96 & 7.2 & 0.720 \\
\hline $10^{-5}$ & -475 & 160 & -158 & 73 & 83.7 & 0.837 \\
\hline $10^{-4}$ & -466 & 95 & -110 & 61 & 90.3 & 0.903 \\
\hline $10^{-3}$ & -455 & 53 & -117 & 53 & 94.6 & 0.946 \\
\hline \multicolumn{7}{|c|}{$\mathrm{Me}-\mathrm{CN} / 1.0 \mathrm{M} \mathrm{HCl} / \mathrm{mild}$ steel } \\
\hline $10^{-6}$ & -480 & 150 & -112 & 59 & 84.7 & 0.847 \\
\hline $10^{-5}$ & -478 & 116 & -113 & 58 & 88.2 & 0.882 \\
\hline $10^{-4}$ & -468 & 69 & -109 & 57 & 93.0 & 0.930 \\
\hline $10^{-3}$ & -470 & 58 & -118 & 51 & 94.1 & 0.941 \\
\hline
\end{tabular}

exponent which measures the deviation from the ideal capacitive behavior [38]. Depending on the values of $n$, CPE can represent resistance $(n=0)$, capacitance $(n=1)$, inductance $(n=-1)$ and Warburg impedance $(n=0.5)$ [39, 40]. The double-layer capacitance values $C_{\mathrm{dl}}$ derived from the CPE and the relaxation time constant $(\tau)$ of charge transfer process can be calculated using Eqs. (27) and (28), respectively [41].

$C_{\mathrm{dl}}=\sqrt[n]{A\left(R_{\mathrm{ct}}\right)^{1-n}}$

$\tau=C_{\mathrm{dl}} R_{\mathrm{ct}}$

The impedance parameters, such as $R_{\mathrm{s}}, R_{\mathrm{ct}}, n, C_{\mathrm{dl}}$ and inhibition efficiency $\eta_{\text {EIS }}(\%)$, obtained from fitting the $E I S$ data using the equivalent circuit of Fig. 3, are calculated and listed in Table 4.

Inspection of the results in Table 4 indicated that $R_{\mathrm{ct}}$ value increased with the concentration of these inhibitors. In addition, the $C_{\mathrm{dl}}$ value varies in the regular manner with triazepine carboxylate compounds concentration. The change in these parameters can be related to the gradual removal of water molecules by $\mathrm{Cl}-\mathrm{Et}-\mathrm{CN}, \mathrm{Me}-\mathrm{CN}$ and $\mathrm{Cl}-\mathrm{Me}-\mathrm{CO}_{2} \mathrm{Et}$ molecules on metallic surface and consequently leads to decrease in the number of active sites necessary for the corrosion reaction.

The increase in $R_{\mathrm{ct}}$ value is also attributed to the formation of protective film on the metal/solution interface. The ongoing stability of ' $n$ ' (in the range of 0.803-0.903) indicates the charge transfer controlled dissolution mechanism of mild steel in the absence and presence of Cl-Et-CN, $\mathrm{Me}-\mathrm{CN}$ and $\mathrm{Cl}-\mathrm{Me}-\mathrm{CO}_{2}$ Et. Moreover, the double-layer capacitance values, $C_{\mathrm{dl}}$, decreased with inhibitors' concentrations which is probably due to a decrease in local dielectric constant and/or an increase in the thickness of ' $e$ ' electrical double layer at mild steel surface. It is know that the removal of water molecules (with high dielectric constant) with inhibitor molecules (with low dielectric constant) from the surface is accompanied by physical interaction between the metal surface and the adsorbate with increasing inhibitor molecules concentration [42]. The thickness of this protective layer (e) is evaluated from the Helmholtz model, given by the following equation [43]:

$C_{\mathrm{dl}}=\frac{\varepsilon_{0} \varepsilon}{e} S$

where $\varepsilon_{0}$ is the permittivity of space, $\varepsilon$ is the local dielectric constant, (e) is the film thickness and $\mathrm{S}$ is the surface area. Equation (30) suggested that $C_{\mathrm{dl}}$ is inversely proportional to the thickness of protective layer (e). So, the decrease in values of $C_{\mathrm{dl}}$ results in increase in values of (e).

On the other hand, the inhibition efficiency of the organic compounds mainly depends on their size and their active centers [27]. Thus, the best performance of compound $\mathrm{Cl}-\mathrm{Me}-\mathrm{CN}$ as corrosion inhibitor over compound $\mathrm{Me}-\mathrm{CN}$ and $\mathrm{Cl}-\mathrm{Me}-\mathrm{CO}_{2} \mathrm{Et}$ may be attributed to the presence of nitrile $(-\mathrm{C} \equiv \mathrm{N})$ cyano group and $-(\mathrm{Cl})$ group. The nucleophilic (electron releasing) character of $-\mathrm{Cl}$ group is highest than the electrophonic (electron with drawing). So, $\mathrm{Cl}-\mathrm{Me}-\mathrm{CN}$ can produce protonated species in $\mathrm{HCl}$ by the reaction of the amino group with hydrochloride acid. This ammonium substituent may reduce the electronic density on the substituted triazepine carboxylate compounds. 

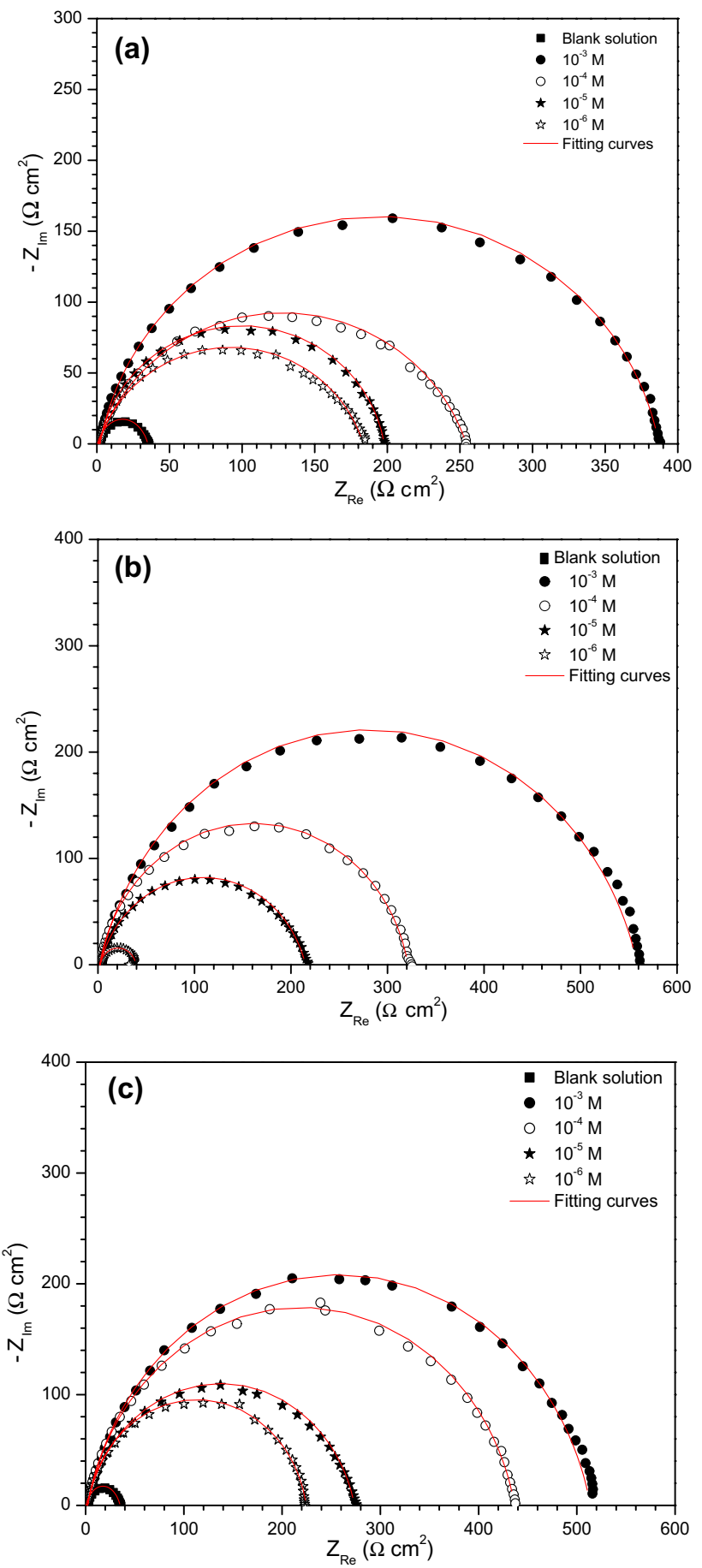

Fig. 2 Nyquist plots for mild steel in $1.0 \mathrm{M} \mathrm{HCl}$ solution in the absence and presence of various concentrations of a $\mathrm{Cl}-\mathrm{Me}-\mathrm{CO}_{2} \mathrm{Et}$, b Cl-Me-CN and c Me-CN at $298 \pm 2 \mathrm{~K}$ : (scatter) experimental; (red line) fitted data

\section{Modeling and analysis by Zview program}

Impedance diagrams were analyzed using Zview program. Bode plots (Figs. 4, 5, 6) exhibit three distinctive segments for mild steel/1.0 M HCl system.

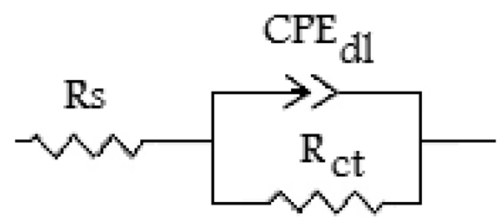

Fig. 3 Electrical equivalent circuits used for modeling the metal/solution interface for the three classes of mild steels

In the higher-frequency region with increasing frequency, the $\log |\mathrm{Z}|$ values tend to become zero and the phase angle values fell rapidly towards $0^{\circ}$. This is a response of resistive behavior and corresponds to the solution resistance.

In the medium-frequency region, a linear relationship between $\log |\mathrm{Z}|$ against $\log f$, with a slop near -1 and the phase angle tends to become $-90^{\circ}$, can be observed. This response is a characteristic of capacitive behavior.

In the low-frequency region, the resistive behavior of the electrode increases, but the region where $\log |\mathrm{Z}|$ does not depend on $\log f$, i.e., dc limit is not completely reached [27].

The fitted data observed by Zview software follow almost the same pattern as the experimental results along the whole diagram with an average error of about $3 \%$ in all cases. The constant phase element (CPE) has a non-integer power dependence on the frequency and is used to compensate the non-homogeneity in a system. Its impedance is described by the expression:

$Z_{\mathrm{CPE}}=\frac{1}{Y(j \omega)^{n}}$

where " $Y$ " is a proportional factor, $j$ equals $\sqrt{-1}$, " $\omega$ " is $2 \pi f$, " $n$ " is the phase shift [38]. For $n=0, Z_{\mathrm{CPE}}$ represents a resistance with $R=Y^{-1}$, for $n=1$ a capacitance with $C=Y$, for $n=0.5$ a Warburg element and for $n=-1$ an inductive with $L=Y^{-1}$ [43].

Because it was observed that the phase shift was closely near " 1 ", the CPE obeys the capacitive behavior and therefore " $Y$ " was substituted with double-layer capacitance $C_{\mathrm{dl}}$. The impedance associated with the circuit is given by:

$Z_{\mathrm{CPE}}=\frac{1}{C_{\mathrm{dl}}(j \omega)^{n}}$

$Z_{\mathrm{T}}=R_{\mathrm{s}}+Z_{1}$

$$
\text { where } \begin{aligned}
Z_{1} & =\left(\frac{1}{Z_{\mathrm{CPE}}}+\frac{1}{R_{\mathrm{ct}}}\right)^{-1} \\
& =\left(C \omega^{n} \cos \frac{n \pi}{2}+j C \omega^{n} \sin \frac{n \pi}{2}+\frac{1}{R_{\mathrm{ct}}}\right)^{-1}
\end{aligned}
$$


Table 4 Electrochemical parameters for mild steel in $1.0 \mathrm{M} \mathrm{HCl}$ in the absence and presence of different concentrations of triazepine carboxylate compounds at $298 \pm 2 \mathrm{~K}$

\begin{tabular}{|c|c|c|c|c|c|c|}
\hline Concentration/M & $R_{\mathrm{s}} / \Omega \mathrm{cm}^{2}$ & $\left.R_{\mathrm{ct}} / \Omega \mathrm{cm}^{2}\right)$ & $C_{\mathrm{dl}} / \mu \mathrm{F} \mathrm{cm}^{-2}$ & $Q / \mu F S^{n-1}$ & $n_{\mathrm{dl}}$ & $\eta_{\mathrm{EIS}} / \%$ \\
\hline \multicolumn{7}{|c|}{ Blank solution (1.0 M HCl/mild steel/without inhibitors) } \\
\hline 00 & $1.35 \pm 0.05$ & $32.68 \pm 0.89$ & $89.42 \pm 3.85$ & $419 \pm 0.028$ & $0.810 \pm 0.01$ & - \\
\hline \multicolumn{7}{|c|}{$\mathrm{Cl}-\mathrm{Me}-\mathrm{CO}_{2} \mathrm{Et} / 1.0 \mathrm{M} \mathrm{HCl} / \mathrm{mild}$ steel } \\
\hline $10^{-6}$ & $1.11 \pm 0.07$ & $182.3 \pm 0.4$ & 126 & $251 \pm 0.2$ & $0.817 \pm 0.01$ & 81.0 \\
\hline $10^{-5}$ & $2.05 \pm 0.07$ & $195.8 \pm 0.4$ & 94.43 & $141.7 \pm 0.1$ & $0.898 \pm 0.01$ & 82.3 \\
\hline $10^{-4}$ & $1.2 \pm 0.09$ & $253.1 \pm 0.4$ & 45.61 & $109.5 \pm 0.2$ & $0.803 \pm 0.01$ & 86.3 \\
\hline $10^{-3}$ & $2.02 \pm 0.08$ & $385 \pm 0.4$ & 78.23 & $117.2 \pm 0.1$ & $0.884 \pm 0.01$ & 91.0 \\
\hline \multicolumn{7}{|c|}{$\mathrm{Cl}-\mathrm{Me}-\mathrm{CN} / 1.0 \mathrm{M} \mathrm{HCl} / \mathrm{mild}$ steel } \\
\hline $10^{-6}$ & $2.21 \pm 0.08$ & $37.2 \pm 0.4$ & 90.11 & $167.6 \pm 0.2$ & $0.891 \pm 0.02$ & 6.7 \\
\hline $10^{-5}$ & $2.3 \pm 0.10$ & $198.6 \pm 0.4$ & 108.2 & $198.8 \pm 0.4$ & $0.838 \pm 0.01$ & 82.5 \\
\hline $10^{-4}$ & $1.7 \pm 0.20$ & $319.3 \pm 0.4$ & 78.15 & $119.6 \pm 0.1$ & $0.884 \pm 0.01$ & 89.1 \\
\hline $10^{-3}$ & $2.1 \pm 0.20$ & $556.6 \pm 0.4$ & 47.49 & $80.53 \pm 0.7$ & $0.854 \pm 0.01$ & 93.7 \\
\hline \multicolumn{7}{|c|}{$\mathrm{Me}-\mathrm{CN} / 1.0 \mathrm{M} \mathrm{HCl} / \mathrm{mild}$ steel } \\
\hline $10^{-6}$ & $2.1 \pm 0.07$ & $222.3 \pm 0.4$ & 104.0 & $149.4 \pm 0.1$ & $0.903 \pm 0.01$ & 84.4 \\
\hline $10^{-5}$ & $1.9 \pm 0.07$ & $271.7 \pm 0.4$ & 91.54 & $150.0 \pm 0.1$ & $0.866 \pm 0.01$ & 87.2 \\
\hline $10^{-4}$ & $2.0 \pm 0.08$ & $434.6 \pm 0.4$ & 68.6 & $105.9 \pm 0.2$ & $0.876 \pm 0.01$ & 92.0 \\
\hline $10^{-3}$ & $1.9 \pm 0.20$ & $511.9 \pm 0.4$ & 50.16 & $80.9 \pm 0.7$ & $0.869 \pm 0.01$ & 93.2 \\
\hline
\end{tabular}

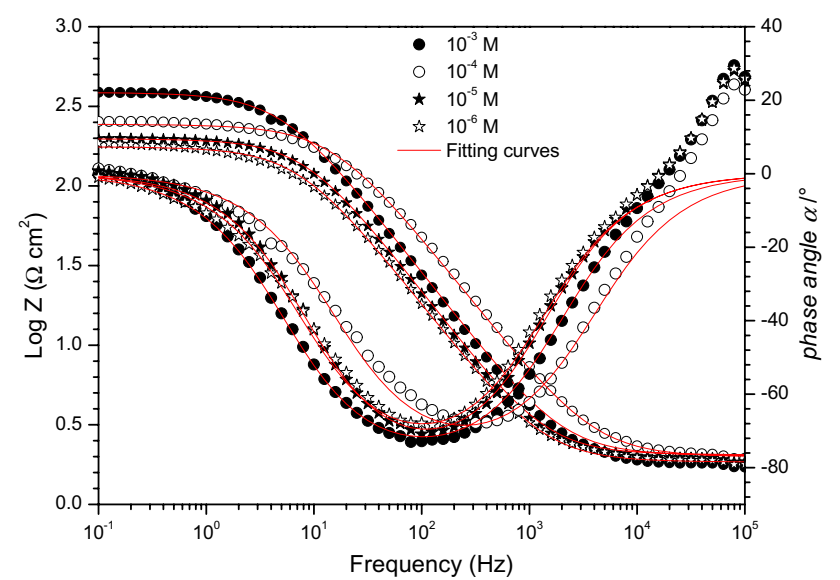

Fig. 4 Bode plots for mild steel in $1.0 \mathrm{M} \mathrm{HCl}$ solution in the absence and presence of various concentrations of $\mathrm{Cl}-\mathrm{Me}-\mathrm{CO}_{2} \mathrm{Et}$ at $E_{\text {corr }}$ $(T=298 \pm 2 \mathrm{~K})$ : comparison of experimental (scatter) and fitting (red line) data

$$
\begin{gathered}
Z_{\mathrm{T}}=R_{\mathrm{S}}+\frac{\left(\frac{1}{R_{\mathrm{Ct}}}\right)+C_{\mathrm{dl}} \omega^{n} \cos \left(\frac{n \pi}{2}\right)}{\frac{1}{R_{\mathrm{Ct}}^{2}}+C_{\mathrm{dl}}^{2} \omega^{2 n}+\left(2 C_{\mathrm{dl}} \omega^{n} \frac{\cos \left(\frac{n \pi}{2}\right)}{R_{\mathrm{Ct}}}\right)} \\
-j \frac{C_{\mathrm{dl}} \omega^{n} \sin \left(\frac{n \pi}{2}\right)}{\frac{1}{R_{\mathrm{Ct}}^{2}}+C_{\mathrm{dl}}^{2} \omega^{2 n}+\left(2 C_{\mathrm{dl}} \omega^{n} \frac{\cos \left(\frac{n \pi}{2}\right)}{R_{\mathrm{Ct}}}\right)}
\end{gathered}
$$

$Z_{\mathrm{T}}$ is the total impedance associated with the circuit. When $\omega \rightarrow \infty: Z_{\mathrm{T}} \rightarrow R_{\mathrm{S}}$ and when $\omega \rightarrow 0: Z_{\mathrm{T}} \rightarrow R_{\mathrm{S}}+R_{\mathrm{ct}}$.

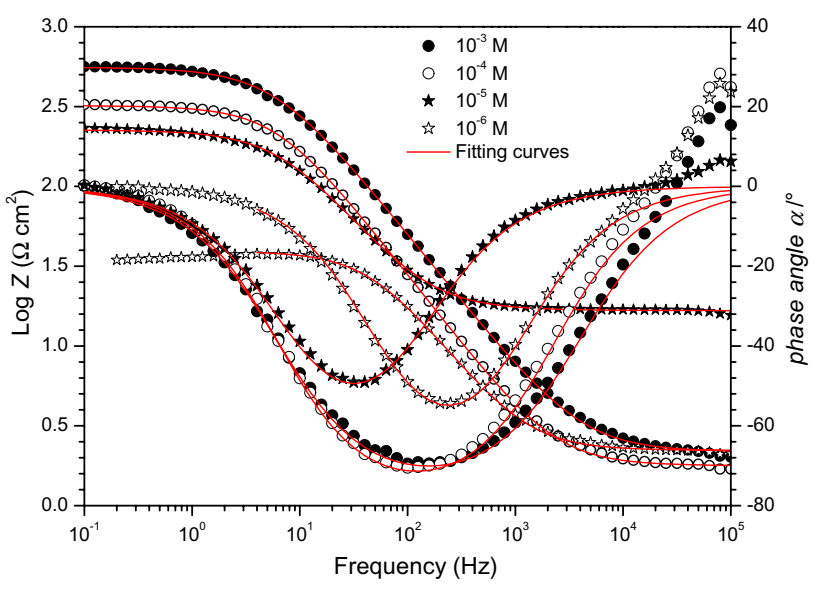

Fig. 5 Bode plots for mild steel in $1.0 \mathrm{M} \mathrm{HCl}$ solution in the absence and presence of various concentrations of $\mathrm{Me}-\mathrm{CN}$ at $E_{\text {corr }}$ $(T=298 \pm 2 \mathrm{~K})$ : comparison of experimental (scatter) and fitting (red line) data

These limits of high and low frequencies, respectively, are both compatible with Nyquist diagram.

Initially, the $R_{\mathrm{S}}$ values were obtained from the higher limit and $R_{\mathrm{ct}}$ values were calculated from the difference in impedance at lower and higher frequencies (these values are written in obtained column of Table 4). $Z_{\text {Imax }}$ and $f_{\max }$ were directly obtained from the impedance data. The phase shift values " $n$ " were calculated using Eq. (6) expression and double-layer capacitance $\left(C_{\mathrm{dl}}\right)$ values were calculated from Eq. (36): 


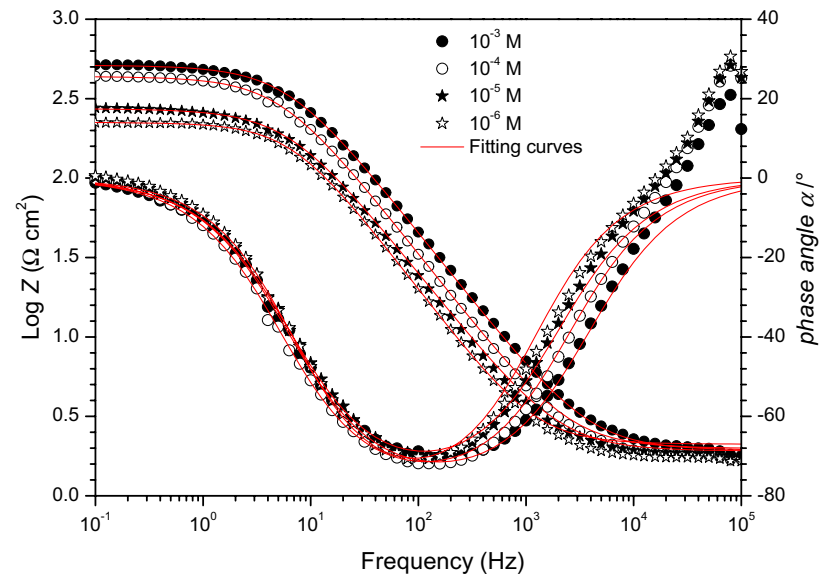

Fig. 6 Bode plots for mild steel in $1.0 \mathrm{M} \mathrm{HCl}$ solution in the absence and presence of various concentrations of $\mathrm{Cl}-\mathrm{Me}-\mathrm{CN}$ at $E_{\text {corr }}$ $(T=298 \pm 2 \mathrm{~K})$ : comparison of experimental (scatter) and fitting (red line) data

$Z_{\text {Imax }}=\frac{R_{\mathrm{ct}} \sin \left(\frac{n \pi}{2}\right)}{2+2 \cos \left(\frac{n \pi}{2}\right)}$

$\omega_{\max }=\frac{1}{\sqrt[2 \mathrm{n}]{R_{\mathrm{ct}}^{2} C_{\mathrm{dl}}^{2}}} \quad$ where $\quad \omega_{\max }=2 \pi f_{\max }$

Table 4 shows the calculated values and difference between these values and the values that were obtained from Zview software. These results confirmed those obtained by potentiodynamic polarization curves.

However, $Q_{\mathrm{dl}}$ is used to replace the double-layer capacitance. Constant phase elements have widely been used to account for deviations brought about by surface roughness such as mentioned above. The use of this parameter, similar to the constant phase element (CPE), allowed the depressed feature of the Nyquist plot to be reproduced readily. Thus, the effective calculated double-layer capacitance $\left(C_{\mathrm{dl}}\right)$ derived from the CPE parameters was determined according to the following equation:

$C_{\mathrm{dl}}=\left(Q_{\mathrm{dl}} \times R_{\mathrm{ct}}^{1-n}\right)^{\frac{1}{n}}$

In addition, it can be observed that the differences in Zview between the calculated and obtained values are high. As a matter of fact, the maximum value that was obtained from the data is not really the maximum value of Nyquist diagram. On the other hand, interpolating the plot data provides closer different maximum values that the calculated values would be more accurate than them. Furthermore, Zview simulation has its own differences compared to real plots. Obtaining the Nyquist plots with more points per decade (Nyquist plots of this investigation obtained with 30 points per decade) to get a value closer to maximum one would lead the investigator to get better results from the calculation.

\section{Quantum chemical calculations}

The calculated quantum chemical parameters of the studied compounds using B3LYP/6-311G $(d, p)$, B3LYP/6$311++\mathrm{G}(d, p)$ and B3LYP/6-311++G $(2 d, 2 p)$ methods in both gas phase (Tables 5) and aqueous phase are presented in Tables 6. In addition, Fig. 7 presents the optimized molecular structure, HOMOs, LUMOs and molecular electrostatic potential maps of neutral forms of triazepine carboxylate. According to the results presented in Tables 5 and 6 in the gaseous and aqueous phases, the $\mathrm{Cl}-\mathrm{Me}-\mathrm{CN}$ molecule can be considered as a better corrosion inhibitor than the other molecules with a low energy gap $(\Delta E)$. Consequently, in terms of the energies of the frontier orbitals, the classification of corrosion inhibition efficiency of the studied molecules can be given as: $\mathrm{Cl}-\mathrm{Me}-\mathrm{CN}>\mathrm{Me}-\mathrm{CN}>\mathrm{Cl}-\mathrm{Me}-\mathrm{CO}_{2} \mathrm{Et}$. This classification is in good agreement with the experimental data.

In addition, the principles based on the chemical hardness concept are very useful in terms of estimating the directions of chemical reactions and understanding of the nature of chemical interactions [21, 44-46]. According to the principle of maximum hardness, a chemical compound tends to be arranged so as to obtain maximum hardness and the chemical hardness can be considered as a measure of stability. Thus, a good corrosion inhibitor is characterized by a low chemical hardness value [47]. According to the hardness values presented in Tables 5 and 6, the classification of inhibition efficiency of the studied molecules can be given as follows: $\mathrm{Cl}-\mathrm{Me}-\mathrm{CN} \approx \mathrm{Me}-\mathrm{CN}>\mathrm{Cl}-\mathrm{Me}-\mathrm{CO}_{2} \mathrm{Et}$ in the both gaseous and aqueous phases. This trend is consistent with that of experimental inhibition efficiencies.

On the other hand, the chemical hardness, softness and energy deviation (AE) are closely associated with each other. It is known also that the softness and the hardness are given on the basis of HOMO and LUMO orbital energies following the Koopman theorem. Thus, it is important to note that an effective inhibitor is characterized by a small energy gap. The order in which the values of the energy gap change is also consistent with the experimental data.

However, electronegativity is a parameter that determines the fraction of the transferred electrons $(\Delta N)$ from the inhibitory molecules to the metallic surface [48]. It can be seen from the equation given below that the value of the transferred electrons of the metal and the inhibitors decreased when the electronegativity of the inhibitor 
Table 5 Calculated quantum chemical parameters for neutral forms of inhibitor molecules in gas phase (eV)

\begin{tabular}{|c|c|c|c|c|c|c|c|c|c|c|c|}
\hline Gas & $E_{\text {номо }}(\mathrm{eV})$ & $E_{\mathrm{LUMO}}(\mathrm{eV})$ & $I$ & $A$ & $\Delta E$ & $\eta$ & $\sigma$ & $\chi$ & $\Omega$ & $\varepsilon$ & Energy $(\mathrm{eV})$ \\
\hline \multicolumn{12}{|l|}{ HF/SDD level } \\
\hline $\mathrm{Cl}-\mathrm{Me}-\mathrm{CO}_{2} \mathrm{Et}$ & -9.01411 & 0.64954 & 9.01411 & -0.64954 & 9.66366 & 4.83183 & 0.20696 & 4.18229 & 1.81003 & 0.55248 & $-54,654.07565$ \\
\hline $\mathrm{Me}-\mathrm{CN}$ & -8.77248 & 0.47920 & 8.77248 & -0.47920 & 9.25167 & 4.62584 & 0.21618 & 4.14664 & 1.85854 & 0.53806 & $-37,437.05053$ \\
\hline $\mathrm{Cl}-\mathrm{Me}-\mathrm{CN}$ & -9.18854 & 0.33008 & 9.18854 & -0.33008 & 9.51862 & 4.75931 & 0.21011 & 4.42923 & 2.06102 & 0.48520 & $-49,923.74066$ \\
\hline \multicolumn{12}{|l|}{$\mathrm{HF} / 6-31 \mathrm{G}$ level } \\
\hline $\mathrm{Cl}-\mathrm{Me}-\mathrm{CO}_{2} \mathrm{Et}$ & -9.01003 & 0.79077 & 9.01003 & -0.79077 & 9.80080 & 4.90040 & 0.20406 & 4.10963 & 1.72323 & 0.58030 & $-54,658.68198$ \\
\hline $\mathrm{Me}-\mathrm{CN}$ & -8.74091 & 0.64355 & 8.74091 & -0.64355 & 9.38446 & 4.69223 & 0.21312 & 4.04868 & 1.74669 & 0.57251 & $-37,440.48460$ \\
\hline $\mathrm{Cl}-\mathrm{Me}-\mathrm{CN}$ & -9.18119 & 0.47811 & 9.18119 & -0.47811 & 9.65930 & 4.82965 & 0.20705 & 4.35154 & 1.96038 & 0.51010 & $-49,928.21302$ \\
\hline \multicolumn{12}{|c|}{$\mathrm{HF} / 6-31++\mathrm{G}$ level } \\
\hline $\mathrm{Cl}-\mathrm{Me}-\mathrm{CO}_{2} \mathrm{Et}$ & -9.03452 & 0.64002 & 9.03452 & -0.64002 & 9.67454 & 4.83727 & 0.20673 & 4.19725 & 1.82096 & 0.54916 & $-54,650.28377$ \\
\hline $\mathrm{Me}-\mathrm{CN}$ & -8.79805 & 0.48382 & 8.79805 & -0.48382 & 9.28188 & 4.64094 & 0.21547 & 4.15712 & 1.86187 & 0.53710 & $-37,433.81058$ \\
\hline $\mathrm{Cl}-\mathrm{Me}-\mathrm{CN}$ & -9.21412 & 0.32681 & 9.21412 & -0.32681 & 9.54093 & 4.77047 & 0.20962 & 4.44365 & 2.06962 & 0.48318 & $-49,920.83242$ \\
\hline \multicolumn{12}{|c|}{ B3LYP/SDD level } \\
\hline $\mathrm{Cl}-\mathrm{Me}-\mathrm{CO}_{2} \mathrm{Et}$ & -6.36643 & -3.01477 & 6.36643 & 3.01477 & 3.35165 & 1.67583 & 0.59672 & 4.69060 & 6.56444 & 0.15234 & $-54,934.82706$ \\
\hline $\mathrm{Me}-\mathrm{CN}$ & -8.79805 & 0.48382 & 8.79805 & -0.48382 & 9.28188 & 4.64094 & 0.21547 & 4.15712 & 1.86187 & 0.53710 & $-37,433.81058$ \\
\hline $\mathrm{Cl}-\mathrm{Me}-\mathrm{CN}$ & -9.21412 & 0.32681 & 9.21412 & -0.32681 & 9.54093 & 4.77047 & 0.20962 & 4.44365 & 2.06962 & 0.48318 & $-49,920.83242$ \\
\hline \multicolumn{12}{|c|}{ B3LYP/6-31G level } \\
\hline $\mathrm{Cl}-\mathrm{Me}-\mathrm{CO}_{2} \mathrm{Et}$ & -6.44507 & -3.00198 & 6.44507 & 3.00198 & 3.44308 & 1.72154 & 0.58087 & 4.72353 & 6.48015 & 0.15432 & $-54,940.29793$ \\
\hline $\mathrm{Me}-\mathrm{CN}$ & -6.46248 & -3.24335 & 6.46248 & 3.24335 & 3.21913 & 1.60957 & 0.62129 & 4.85292 & 7.31588 & 0.13669 & $-37,667.29933$ \\
\hline $\mathrm{Cl}-\mathrm{Me}-\mathrm{CN}$ & -6.63691 & -3.27709 & 6.63691 & 3.27709 & 3.35982 & 1.67991 & 0.59527 & 4.95700 & 7.31345 & 0.13673 & $-50,181.59035$ \\
\hline \multicolumn{12}{|c|}{ B3LYP/6-31++G level } \\
\hline $\mathrm{Cl}-\mathrm{Me}-\mathrm{CO}_{2} \mathrm{Et}$ & -6.50847 & -3.10158 & 6.50847 & 3.10158 & 3.40689 & 1.70345 & 0.58705 & 4.80502 & 6.77693 & 0.14756 & $-54,931.01765$ \\
\hline $\mathrm{Me}-\mathrm{CN}$ & -6.46248 & -3.24335 & 6.46248 & 3.24335 & 3.21913 & 1.60957 & 0.62129 & 4.85292 & 7.31588 & 0.13669 & $-37,667.29941$ \\
\hline $\mathrm{Cl}-\mathrm{Me}-\mathrm{CN}$ & -6.71201 & -3.38920 & 6.71201 & 3.38920 & 3.32281 & 1.66140 & 0.60190 & 5.05061 & 7.67683 & 0.13026 & $-50,173.38557$ \\
\hline
\end{tabular}

increases. According to Pearson, the fraction of electrons transferred from a corrosion inhibitor to a metal atom can be calculated by the following Eq. (38):

$$
\Delta N=\frac{\chi_{\mathrm{M}}-\chi_{\mathrm{inh}}}{2\left(\eta_{\mathrm{M}}+\eta_{\mathrm{inh}}\right)}
$$

where $\chi_{\mathrm{M}}$ and $\chi_{\text {inh }}$ are electronegativity of metal and the electronegativity of inhibitor, respectively. $\eta_{\mathrm{M}}$ and $\eta_{\text {inh }}$ represent the chemical hardness value of metal and chemical hardness value of inhibitor, respectively.

According to the electronegativity and chemical potential values of the inhibitor molecules, the corrosion inhibition efficiencies follow the order: $\mathrm{Cl}-\mathrm{Me}-\mathrm{CN} \approx \mathrm{Me}-\mathrm{CN}>\mathrm{Cl}-\mathrm{Me}-\mathrm{CO}_{2} \mathrm{Et}$ in gas phase and $\mathrm{Cl}-\mathrm{Me}-\mathrm{CO}_{2} \mathrm{Et}>\mathrm{Me}-\mathrm{CN} \approx \mathrm{Cl}-\mathrm{Me}-\mathrm{CN}$ aqueous phase (Tables 5 and 6).

On the other hand, electrophilicity is a useful parameter for predicting the tendency of the inhibitor molecules to accept electrons. For this reason, it should be stated that a molecule that has a high electrophilicity value is ineffective against corrosion.

The trend in which the electrophilicity values increase is as follows: $\mathrm{Cl}-\mathrm{Me}-\mathrm{CN} \approx \mathrm{Me}-\mathrm{CN}>\mathrm{Cl}-\mathrm{Me}-\mathrm{CO}_{2} \mathrm{Et}$. Within the framework of this information, we can write the corrosion inhibition efficiency ranking of the molecules as: $\mathrm{Cl}-\mathrm{Me}-\mathrm{CN} \approx \mathrm{Me}-\mathrm{CN}>\mathrm{Cl}-\mathrm{Me}-\mathrm{CO}_{2} \mathrm{Et}$ in gas phase and $\mathrm{Cl}-\mathrm{Me}-\mathrm{CO}_{2} \mathrm{Et}>\mathrm{Cl}-\mathrm{Me}-\mathrm{CN}>\mathrm{Me}-\mathrm{CN}$ aqueous phase (Tables 5 and 6). This ranking is compatible with the experimental inhibition efficiency ranking for gas phase.

On the other hand, the presence of the heteroatoms such as oxygen and nitrogen in the molecules of triazepine carboxylate leads to a high tendency for protonation in acidic medium. Thus, analysis of the protonated forms of triazepine carboxylate compounds is important in terms of the calculation of the proton affinities of neutral inhibitors. Quantum chemical parameters calculated in both gas phase and aqueous phase for protonated inhibitors are given in Tables 7 and 8. To determine the most appropriate heteroatom for protonation, the studied triazepine carboxylate has been protonated from different regions. It should be noted that a chemical compound with high proton affinity acts as a good corrosion inhibitor. If so, according to proton affinity values given in Tables 7 and 8, the corrosion inhibition efficiencies of the studied compounds follow the order: $\mathrm{Cl}-\mathrm{Me}-\mathrm{CN}>\mathrm{Me}-\mathrm{CN}>\mathrm{Cl}-\mathrm{Me}-\mathrm{CO}_{2} \mathrm{Et}$. Proton affinity values obtained have been calculated considering Eqs. (39) and (40):

$\mathrm{PA}=E_{(\text {pro })}-\left(E_{(\text {non-pro })}+E_{\mathrm{H}^{+}}\right)$ 
Table 6 Calculated quantum chemical parameters for neutral forms of inhibitor molecules in aqueous phase (eV)

\begin{tabular}{|c|c|c|c|c|c|c|c|c|c|c|c|}
\hline WATER & $E_{\text {Номо }}(\mathrm{eV})$ & $E_{\text {LUMO }}(\mathrm{eV})$ & $I$ & $A$ & $\Delta E$ & $\eta$ & $\sigma$ & $\chi$ & $\Omega$ & $\varepsilon$ & Energy (eV) \\
\hline \multicolumn{12}{|l|}{ HF/SDD level } \\
\hline $\mathrm{Cl}-\mathrm{Me}-\mathrm{CO}_{2} \mathrm{Et}$ & -8.98228 & 0.81852 & 8.98228 & -0.81852 & 9.80080 & 4.90040 & 0.20406 & 4.08188 & 1.70004 & 0.58822 & $-54,655.10626$ \\
\hline $\mathrm{Me}-\mathrm{CN}$ & -8.69492 & 0.73961 & 8.69492 & -0.73961 & 9.43453 & 4.71727 & 0.21199 & 3.97766 & 1.67700 & 0.59630 & $-37,438.09276$ \\
\hline $\mathrm{Cl}-\mathrm{Me}-\mathrm{CN}$ & -9.02963 & 0.71458 & 9.02963 & -0.71458 & 9.74420 & 4.87210 & 0.20525 & 4.15752 & 1.77388 & 0.56374 & $-49,924.88733$ \\
\hline \multicolumn{12}{|l|}{$\mathrm{HF} / 6-31 \mathrm{G}$ level } \\
\hline $\mathrm{Cl}-\mathrm{Me}-\mathrm{CO}_{2} \mathrm{Et}$ & -8.97248 & 0.95594 & 8.97248 & -0.95594 & 9.92842 & 4.96421 & 0.20144 & 4.00827 & 1.61820 & 0.61797 & $-54,659.68453$ \\
\hline $\mathrm{Me}-\mathrm{CN}$ & -8.66635 & 0.88274 & 8.66635 & -0.88274 & 9.54909 & 4.77455 & 0.20944 & 3.89180 & 1.58613 & 0.63046 & $-37,441.45241$ \\
\hline $\mathrm{Cl}-\mathrm{Me}-\mathrm{CN}$ & -9.01956 & 0.83131 & 9.01956 & -0.83131 & 9.85087 & 4.92544 & 0.20303 & 4.09412 & 1.70156 & 0.58770 & $-49,929.21106$ \\
\hline \multicolumn{12}{|c|}{ HF/6-31++G level } \\
\hline $\mathrm{Cl}-\mathrm{Me}-\mathrm{CO}_{2} \mathrm{Et}$ & -8.99207 & 0.80029 & 8.99207 & -0.80029 & 9.79237 & 4.89618 & 0.20424 & 4.09589 & 1.71320 & 0.58370 & $-54,651.32146$ \\
\hline $\mathrm{Me}-\mathrm{CN}$ & -8.69982 & 0.72845 & 8.69982 & -0.72845 & 9.42828 & 4.71414 & 0.21213 & 3.98568 & 1.68490 & 0.59351 & $-37,434.83836$ \\
\hline $\mathrm{Cl}-\mathrm{Me}-\mathrm{CN}$ & -9.04160 & 0.69607 & 9.04160 & -0.69607 & 9.73767 & 4.86884 & 0.20539 & 4.17276 & 1.78810 & 0.55925 & $-49,921.95169$ \\
\hline \multicolumn{12}{|c|}{ B3LYP/SDD level } \\
\hline $\mathrm{Cl}-\mathrm{Me}-\mathrm{CO}_{2} \mathrm{Et}$ & -6.28887 & -2.92770 & 6.28887 & 2.92770 & 3.36118 & 1.68059 & 0.59503 & 4.60828 & 6.31811 & 0.15828 & $-54,935.66425$ \\
\hline $\mathrm{Me}-\mathrm{CN}$ & -6.20044 & -3.02130 & 6.20044 & 3.02130 & 3.17913 & 1.58957 & 0.62910 & 4.61087 & 6.68740 & 0.14953 & $-37,671.14798$ \\
\hline $\mathrm{Cl}-\mathrm{Me}-\mathrm{CN}$ & -6.36180 & -3.06103 & 6.36180 & 3.06103 & 3.30077 & 1.65038 & 0.60592 & 4.71142 & 6.72494 & 0.14870 & $-50,177.10858$ \\
\hline \multicolumn{12}{|c|}{ B3LYP/6-31G level } \\
\hline $\mathrm{Cl}-\mathrm{Me}-\mathrm{CO}_{2} \mathrm{Et}$ & -6.44507 & -3.00198 & 6.44507 & 3.00198 & 3.44308 & 1.72154 & 0.58087 & 4.72353 & 6.48015 & 0.15432 & $-54,940.29793$ \\
\hline $\mathrm{Me}-\mathrm{CN}$ & -6.23227 & -2.95763 & 6.23227 & 2.95763 & 3.27464 & 1.63732 & 0.61075 & 4.59495 & 6.44759 & 0.15510 & $-37,675.45179$ \\
\hline $\mathrm{Cl}-\mathrm{Me}-\mathrm{CN}$ & -6.40806 & -3.00960 & 6.40806 & 3.00960 & 3.39846 & 1.69923 & 0.58850 & 4.70883 & 6.52446 & 0.15327 & $-50,182.34689$ \\
\hline \multicolumn{12}{|c|}{ B3LYP/6-31++G level } \\
\hline $\mathrm{Cl}-\mathrm{Me}-\mathrm{CO}_{2} \mathrm{Et}$ & -6.50847 & -3.10158 & 6.50847 & 3.10158 & 3.40689 & 1.70345 & 0.58705 & 4.80502 & 6.77693 & 0.14756 & $-54,931.01765$ \\
\hline $\mathrm{Me}-\mathrm{CN}$ & -6.30193 & -3.06484 & 6.30193 & 3.06484 & 3.23709 & 1.61855 & 0.61784 & 4.68339 & 6.77587 & 0.14758 & $-37,668.10602$ \\
\hline $\mathrm{Cl}-\mathrm{Me}-\mathrm{CN}$ & -6.71201 & -3.38920 & 6.71201 & 3.38920 & 3.32281 & 1.66140 & 0.60190 & 5.05061 & 7.67683 & 0.13026 & $-50,173.38557$ \\
\hline
\end{tabular}

where $E_{\text {non-pro }}$ and $E_{\text {pro }}$ are the energies of the non-protonated and protonated inhibitors, respectively. $E_{\mathrm{H}}^{+}$is the energy of $\mathrm{H}^{+}$ion and was calculated as:

$E_{\mathrm{H}^{+}}=E_{\left(\mathrm{H}_{3} \mathrm{O}^{+}\right)}-E_{\left(\mathrm{H}_{2} \mathrm{O}\right)}$

As can be seen from Tables 7 and 8, the classification of the inhibition efficiencies to be interpreted using the electrophilicity values of the protonated molecules is the same as those of the non-protonated forms: $\mathrm{Cl}-\mathrm{Me}-\mathrm{CN}>\mathrm{Me}-\mathrm{CN}>\mathrm{Cl}-\mathrm{Me}-\mathrm{CO}_{2} \mathrm{Et}$.

To conclude, the results obtained for quantum chemical calculations are generally compatible with experimental results. Considering the results obtained in the theoretical section of this study, it is found that the corrosion inhibition efficiency follows the order: $\mathrm{Cl}-\mathrm{Me}-\mathrm{CN}>\mathrm{Me}-\mathrm{CN}>\mathrm{Cl}-\mathrm{Me}-\mathrm{CO}_{2} \mathrm{Et}$.

\section{Molecular dynamic study}

Molecular dynamic simulations study was employed to provide a significant relationship between molecular structure of triazepine carboxylate inhibitors molecules and their inhibition efficiency [49, 50] adsorption mode and ability [51].
The lowest energy configuration results from Monte Carlo simulation are presented in Fig. 8. Data from MD modeling for adsorption of triazepine carboxylate compounds on Fe (110) are listed in Table 9. Furthermore, outputs and descriptors calculated by the Monte Carlo simulation are given in Table 10.

As can be inferred from the results in Table 9, the adsorption energies of the investigated molecules increased in the following order $\mathrm{Cl}-\mathrm{Me}-\mathrm{CN}<\mathrm{Me}-\mathrm{CN}<\mathrm{Cl}-\mathrm{Me}-\mathrm{CO}_{2} \mathrm{Et}$, and $\mathrm{Cl}-\mathrm{Me}-\mathrm{CN}$ shows the maximum negative adsorption energy. Therefore, $\mathrm{Cl}-\mathrm{Me}-\mathrm{CN}$ provides the highest inhibition abilities as compared to the other two triazepine carboxylate inhibitors. These findings confirmed the observations from quantum computational and the experimental results.

Mild steel surface is accumulated with negative charge when immersed into $\mathrm{HCl}$ media because chloride ions $\left(\mathrm{Cl}^{-}\right)$ adsorb on the metal surface according to Eq. (41) below:

$\mathrm{Fe}+\mathrm{Cl}^{-} \leftrightarrow\left[\mathrm{FeCl}^{-}\right]_{\mathrm{ads}}$

In acid solutions, triazepine carboxylate compounds could be easily protonated (reaction (42)), due to high electron density on it, leading to positively charged inhibitor species. 

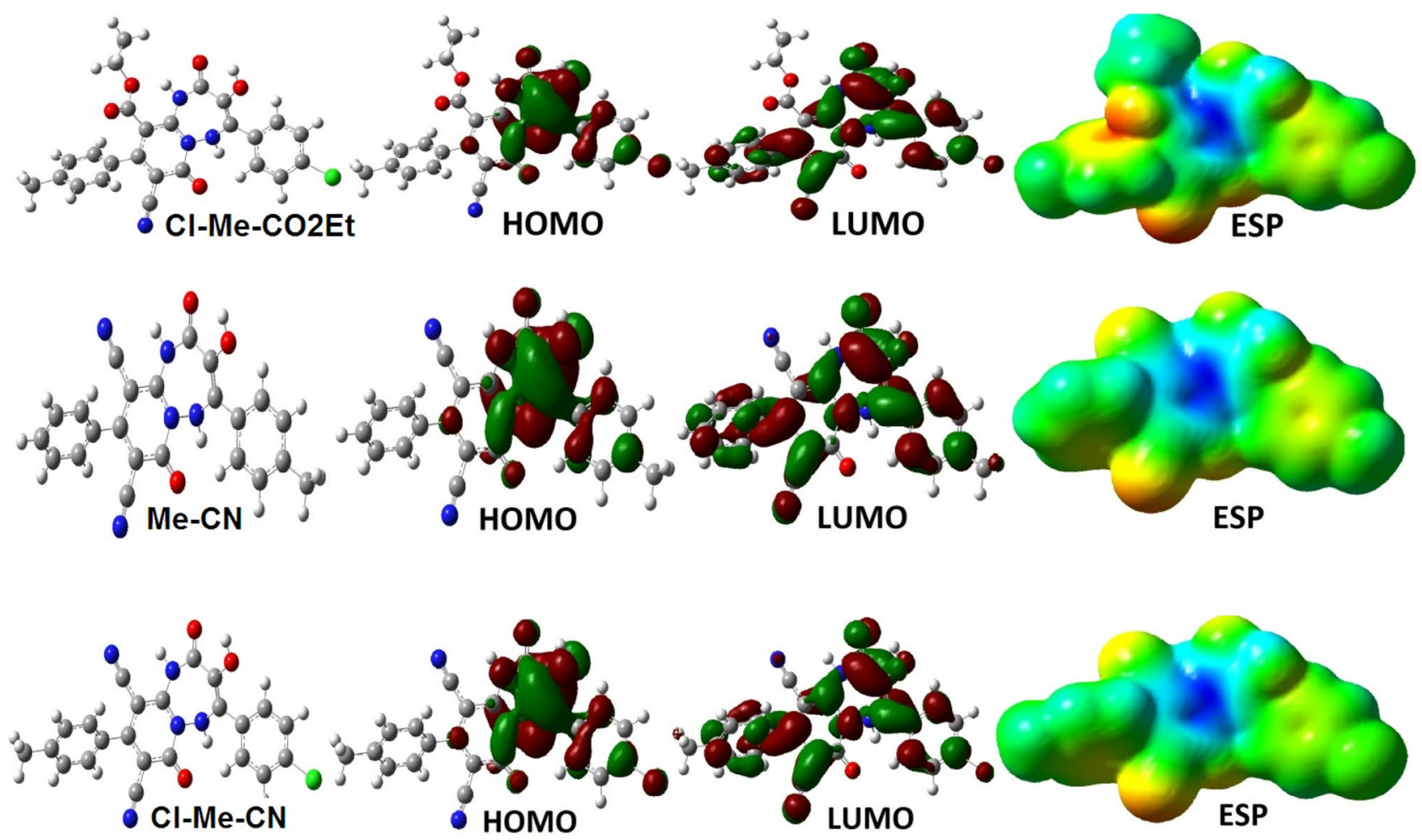

Fig. 7 The optimized structures, HOMOs, LUMOs and electrostatic potential structures of non-protonated inhibitor molecules using DFT/ B3LYP/6-31++G $(d, p)$

$[\mathrm{Cl}-\mathrm{Me}-\mathrm{CN}]+\mathrm{H}^{+} \leftrightarrow[\mathrm{Cl}-\mathrm{Me}-\mathrm{CN}]^{+}$

The physical adsorption could occur via electrostatic interaction between protonated inhibitor molecules and negatively charged mild steel surface. The unshared electron pairs on $(\mathrm{O}, \mathrm{N})$ heteroatoms along with $\pi$-electrons of aromatic systems and multiple bonds contribute virtually in the adsorption process. Besides, chemical adsorption could occur via interaction of $\pi$-electrons of the aromatic rings of inhibitor with vacant $d$-orbitals of mild steel, resulting in formation of coordinate type of bond. $\mathrm{Cl}-\mathrm{Me}-\mathrm{CN}$ was the most efficient one because it has the highest molecular weight $(443 \mathrm{~g} / \mathrm{mol})$ and contains $5 \mathrm{~N}$ and $3 \mathrm{O}$ atom which is less electronegative and more basic than $\mathrm{N}$ and $\mathrm{O}$ atoms, so it shares more electrons to the molecule than $\mathrm{N}$ and $\mathrm{O}$ atoms. $\mathrm{Me}-\mathrm{CN}$ compound comes after $\mathrm{Cl}-\mathrm{Me}-\mathrm{CN}$ in $\% \eta$ because of the molecular size $(409 \mathrm{~g} / \mathrm{mol})$.

The pair correlation function $g(r)$ was used to characterize the degree of atom disorder in the molecule and can give a measure of the probability of finding a pair of atoms at a given distance $(r)$ in a random distribution. The pair correlation function has been applied in structural investigations of interaction between the liquid and solid materials and in studying specific interactions such as hydrogen bonding. The $g(r)$ of the super molecular system is obtained through analyzing the trajectory output of molecular dynamic simulation [52]. In this part, we will consider the distribution of heteroatoms ( $\mathrm{N}$ and $\mathrm{O}$ ) according to their importance on the adsorption process of chemical compounds on the metal surface. The pair correlation function, $g(r)$, of $\mathrm{N}$ and $\mathrm{O}$ of triazepine carboxylate compounds atoms and iron surface atoms is displayed in Fig. 8. The radial distribution function (RDF) $g(r)$ is a modern tool used as measure of bond length which provides an indication of the type of interaction of inhibitor molecules on metal surface. In literature, when the first peak occurs at 1-3.5 $\AA$, this implies the chemisorption, whereas the physisorption is associated with the peaks longer than $3.5 \AA$. The radial distribution function of heteroatoms of inhibitors graphically presented in Fig. 9 shows that all the bond lengths are less than $3.5 \AA$, so chemical interactions might occur between these atoms and the metallic surface.

The adsorption mode of investigated derivatives on Fe (1 1 0) surface was studied by the molecular dynamics simulation method. At the molecular level, the most stable configuration of the molecules on the metal surface and the values of the adsorption ( $\left.E_{\text {adsorption }}\right)$ between organic inhibitor and the metal surface are the results of the simulation process [53]. The most stable (lowest energy) configurations of the tested compounds on $\mathrm{Fe}$ (110) surfaces are depicted in Fig. 8. It was observed that the heteroatoms of the compounds adsorbed on 
Table 7 Calculated quantum chemical parameters for protonated molecules in gas phase (eV)

\begin{tabular}{|c|c|c|c|c|c|c|c|c|c|c|c|}
\hline $\begin{array}{l}\text { Protonated } \\
\text { molecules in gas } \\
\text { phase }\end{array}$ & $E_{\mathrm{HOMO}}(\mathrm{eV})$ & $E_{\text {LUMO }}(\mathrm{eV})$ & $I$ & $A$ & $\Delta E$ & $\eta$ & $\sigma$ & $\chi$ & $\omega$ & $\varepsilon$ & Energy $(\mathrm{eV})$ \\
\hline \multicolumn{12}{|l|}{ HF/SDD level } \\
\hline $\mathrm{Cl}-\mathrm{Me}-\mathrm{CO}_{2} \mathrm{Et}$ & -11.68221 & -2.87191 & 11.68221 & 2.87191 & 8.81030 & 4.40515 & 0.22701 & 7.27706 & 6.01065 & 0.16637 & $-54,662.22071$ \\
\hline $\mathrm{Me}-\mathrm{CN}$ & -12.17420 & -3.12498 & 12.17420 & 3.12498 & 9.04922 & 4.52461 & 0.22101 & 7.64959 & 6.46644 & 0.15464 & $-37,445.08889$ \\
\hline $\mathrm{Cl}-\mathrm{Me}-\mathrm{CN}$ & -12.01909 & -3.22621 & 12.01909 & 3.22621 & 8.79288 & 4.39644 & 0.22746 & 7.62265 & 6.60816 & 0.15133 & $-49,931.59703$ \\
\hline \multicolumn{12}{|l|}{$\mathrm{HF} / 6-31 \mathrm{G}$ level } \\
\hline $\mathrm{Cl}-\mathrm{Me}-\mathrm{CO}_{2} \mathrm{Et}$ & -11.67269 & -2.74946 & 11.67269 & 2.74946 & 8.92323 & 4.46161 & 0.22413 & 7.21107 & 5.82744 & 0.17160 & $-54,666.92361$ \\
\hline $\mathrm{Me}-\mathrm{CN}$ & -12.18345 & -2.97885 & 12.18345 & 2.97885 & 9.20460 & 4.60230 & 0.21728 & 7.58115 & 6.24404 & 0.16015 & $-37,448.62784$ \\
\hline $\mathrm{Cl}-\mathrm{Me}-\mathrm{CN}$ & -12.00957 & -3.09586 & 12.00957 & 3.09586 & 8.91370 & 4.45685 & 0.22437 & 7.55272 & 6.39953 & 0.15626 & $-49,936.17492$ \\
\hline \multicolumn{12}{|l|}{$\mathrm{HF} / 6-31++\mathrm{G}$ level } \\
\hline $\mathrm{Cl}-\mathrm{Me}-\mathrm{CO}_{2} \mathrm{Et}$ & -11.69065 & -2.86103 & 11.69065 & 2.86103 & 8.82962 & 4.41481 & 0.22651 & 7.27584 & 5.99548 & 0.16679 & $-54,658.47759$ \\
\hline $\mathrm{Me}-\mathrm{CN}$ & -12.22182 & -3.09233 & 12.22182 & 3.09233 & 9.12949 & 4.56475 & 0.21907 & 7.65707 & 6.42213 & 0.15571 & $-37,441.89120$ \\
\hline $\mathrm{Cl}-\mathrm{Me}-\mathrm{CN}$ & -12.01583 & -3.21124 & 12.01583 & 3.21124 & 8.80459 & 4.40229 & 0.22715 & 7.61353 & 6.58360 & 0.15189 & $-49,928.73358$ \\
\hline \multicolumn{12}{|c|}{ B3LYP/SDD level } \\
\hline $\mathrm{Cl}-\mathrm{Me}-\mathrm{CO}_{2} \mathrm{Et}$ & -9.45739 & -6.58630 & 9.45739 & 6.58630 & 2.87110 & 1.43555 & 0.69660 & 8.02184 & 22.41304 & 0.04462 & $-54,943.41586$ \\
\hline $\mathrm{Me}-\mathrm{CN}$ & -9.82638 & -6.77759 & 9.82638 & 6.77759 & 3.04879 & 1.52439 & 0.65600 & 8.30199 & 22.60669 & 0.04423 & $-37,678.77961$ \\
\hline $\mathrm{Cl}-\mathrm{Me}-\mathrm{CN}$ & -9.80706 & -6.88617 & 9.80706 & 6.88617 & 2.92089 & 1.46045 & 0.68472 & 8.34661 & 23.85091 & 0.04193 & $-50,184.62709$ \\
\hline \multicolumn{12}{|c|}{ B3LYP/6-31G level } \\
\hline $\mathrm{Cl}-\mathrm{Me}-\mathrm{CO}_{2} \mathrm{Et}$ & -9.51862 & -6.58874 & 9.51862 & 6.58874 & 2.92987 & 1.46494 & 0.68262 & 8.05368 & 22.13809 & 0.04517 & $-54,948.90686$ \\
\hline $\mathrm{Me}-\mathrm{CN}$ & -9.91808 & -6.75093 & 9.91808 & 6.75093 & 3.16716 & 1.58358 & 0.63148 & 8.33450 & 21.93259 & 0.04559 & $-37,683.13912$ \\
\hline $\mathrm{Cl}-\mathrm{Me}-\mathrm{CN}$ & -9.87863 & -6.87719 & 9.87863 & 6.87719 & 3.00144 & 1.50072 & 0.66635 & 8.37791 & 23.38522 & 0.04276 & $-50,189.87435$ \\
\hline \multicolumn{12}{|c|}{ B3LYP/6-31++G level } \\
\hline $\mathrm{Cl}-\mathrm{Me}-\mathrm{CO}_{2} \mathrm{Et}$ & -9.52596 & -6.65405 & 9.52596 & 6.65405 & 2.87191 & 1.43596 & 0.69640 & 8.09001 & 22.78908 & 0.04388 & $-54,939.50082$ \\
\hline $\mathrm{Me}-\mathrm{CN}$ & -9.95101 & -6.84290 & 9.95101 & 6.84290 & 3.10811 & 1.55405 & 0.64348 & 8.39696 & 22.68545 & 0.04408 & $-37,675.63430$ \\
\hline $\mathrm{Cl}-\mathrm{Me}-\mathrm{CN}$ & -9.87754 & -6.95882 & 9.87754 & 6.95882 & 2.91872 & 1.45936 & 0.68523 & 8.41818 & 24.27977 & 0.04119 & $-50,181.59174$ \\
\hline
\end{tabular}

the iron at first. Then, the remaining centers of the compounds moved gradually close to the metal surface. Therefore, as seen in Fig. 8, the studied molecules $\mathrm{Cl}-\mathrm{Me}-\mathrm{CN}$, and $\mathrm{Me}-\mathrm{CN}$ adsorbed on the Fe surfaces with an almost flat orientation, where compound $\mathrm{Cl}-\mathrm{Me}-\mathrm{CO}_{2} \mathrm{Et}$ is not fully oriented in flat position on metal surface. The parallel configuration as in compound $\mathrm{Cl}-\mathrm{Me}-\mathrm{CN}$ and $\mathrm{Me}-\mathrm{CN}$ supports the maximum surface coverage and the higher binding interaction.

The values of $E_{\text {ads }}$ are large and negative which imply that the binding between the investigated inhibitors and the metal surface is spontaneous, and more negative values of the adsorption energy can be attributed to the stable and strong interaction of the inhibitor on the metal surface [54]. It is observed in Table 10 that the binding energy of $\mathrm{Cl}-\mathrm{Me}-\mathrm{CN}$ on the iron surface is higher than the energy determined for $\mathrm{H}_{3} \mathrm{O}^{+}$and $\mathrm{Cl}^{-}$. This supports that the inhibitors are stable on the iron surface than other competing species. It has been reported that the organic inhibitors with unoccupied orbitals promote the formation of a chelate on the metal surface by accepting electrons from a $d$-orbital of the metal during such strong adsorption process [55]. Therefore, the compound $\mathrm{Cl}-\mathrm{Me}-\mathrm{CO}_{2} \mathrm{Et}$ and $\mathrm{Me}-\mathrm{CN}$ can form a stable chelate with iron after strong adsorption, and this leads to good corrosion inhibition efficiency.

\section{Surface morphology analysis}

The surface morphology of mild steel due to corrosion process was confirmed by the SEM images of the polished and corroded mild steel surface in the absence (Fig. 9a) and presence of inhibitors (Fig. 9b). Figure 9a represents the SEM image for mild steel surface in $1.0 \mathrm{M} \mathrm{HCl}$ without inhibitors. It was found that the surface morphologies served as a good indicator of the severity of corrosion attack. However, SEM images of mild steel surface in the presence of inhibitors (Fig. 9b) were observed to be smoother than that of mild surface in $1.0 \mathrm{M} \mathrm{HCl}$ alone (Fig. 9a).

\section{Three-dimensional optical profiler images}

The 3D optical profiler images of the steels surface in the absence and the presence of triazepine carboxylate $(\mathrm{Cl}-\mathrm{Me}-\mathrm{CN})$ in $1.0 \mathrm{M} \mathrm{HCl}$ are shown in Fig. 10a, b respectively. The surface morphology revealed the formation of the 


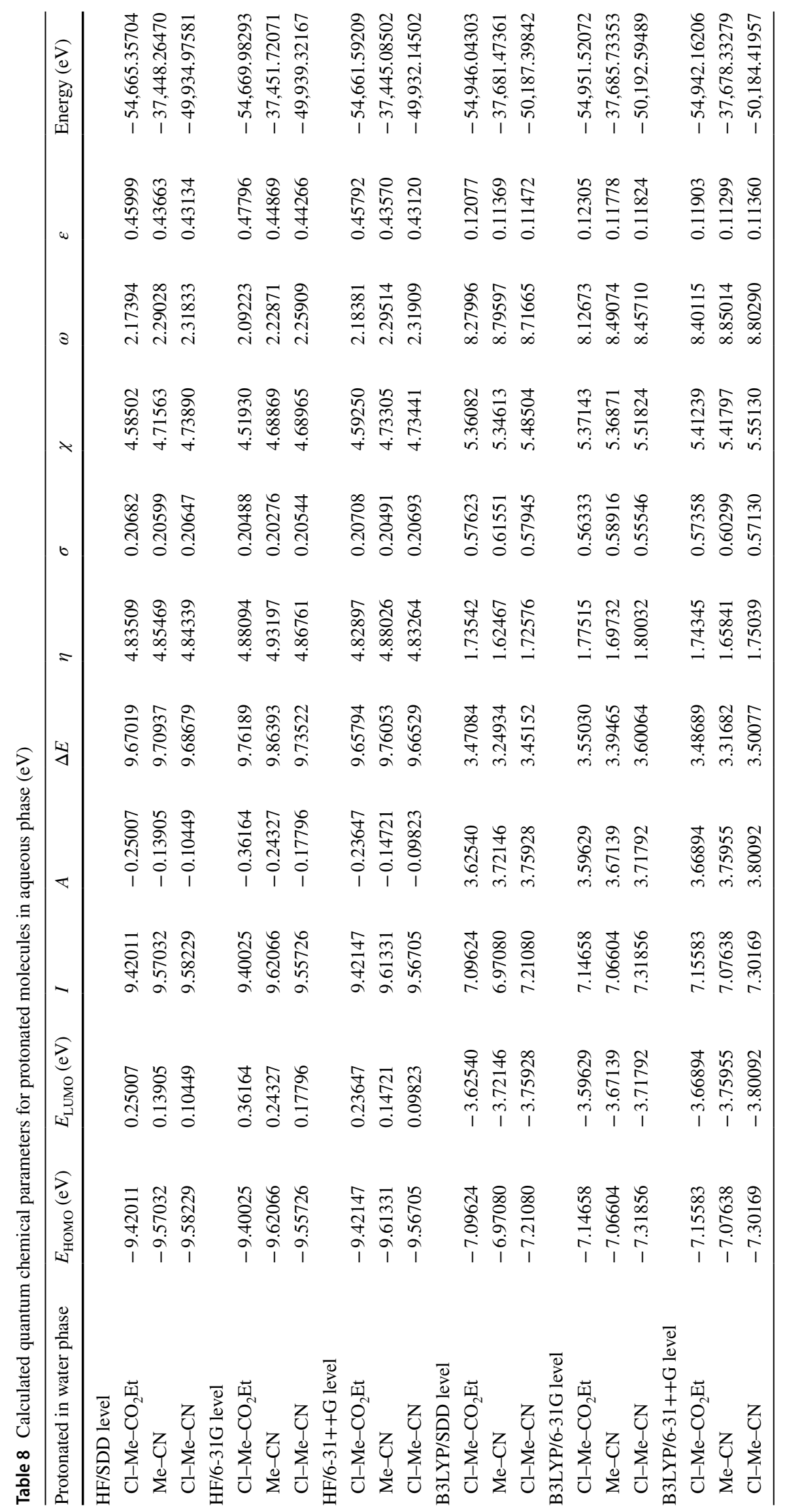



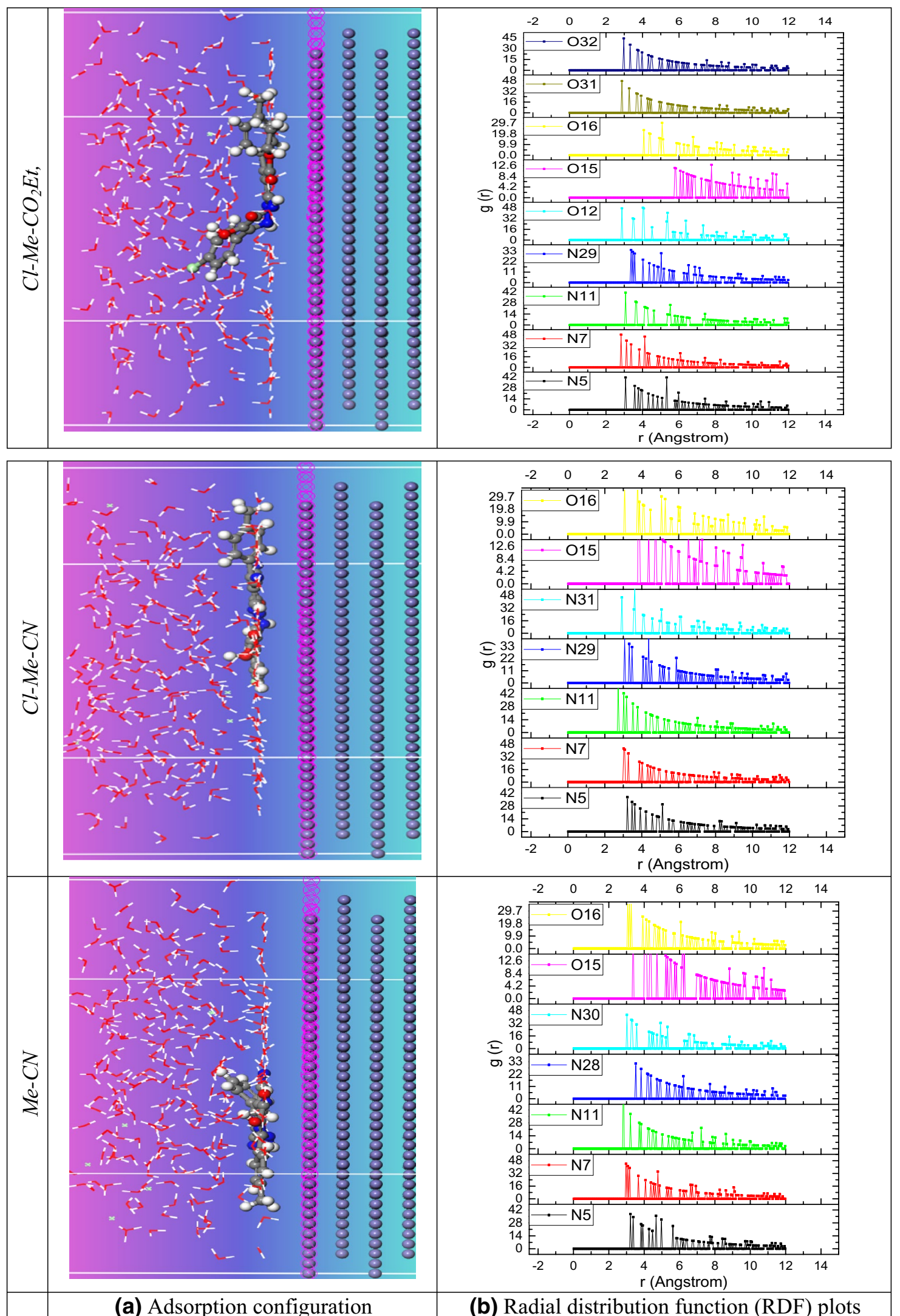

Fig. 8 a Equilibrium configuration adsorption of investigated triazepine carboxylate compounds on $\mathrm{Fe}$ (110) surface in $\mathrm{HCl}$ solution. b Radial distribution function (RDF) of $\mathrm{N}$ and $\mathrm{O}$ atoms from investigated compounds and $\mathrm{Fe}$ atoms from $\mathrm{Fe}(110)$ 
Table 9 Data from MD modeling for adsorption of triazepine carboxylate compounds on Fe (110)

\begin{tabular}{llllll}
\hline System & $\begin{array}{l}\text { Total energy } \\
\left(\mathrm{kcal} \mathrm{mol}^{-1}\right)\end{array}$ & $\begin{array}{l}\text { Adsorption energy } \\
\left(\mathrm{kcal} \mathrm{mol}^{-1}\right)\end{array}$ & $\begin{array}{l}\text { Rigid adsorption energy } \\
\left(\mathrm{kcal} \mathrm{mol}^{-1}\right)\end{array}$ & $\begin{array}{l}\text { Deformation energy } \\
\left(\mathrm{kcal} \mathrm{mol}^{-1}\right)\end{array}$ & $\begin{array}{c}\mathrm{Compound} \mathrm{d} E_{\mathrm{ad}} / \mathrm{d} N_{i} \\
\mathrm{Cl}-\mathrm{Me}-\mathrm{CO}_{2} \mathrm{Et} / \mathrm{Fe}(110)\end{array}$ \\
$\mathrm{Cl}-\mathrm{Me}-\mathrm{CN} / \mathrm{Fe}(110)$ & -4259.60 & -4393.57 & -4319.52 & -74.05 & -233.78 \\
$\mathrm{Me}-\mathrm{CN} / \mathrm{Fe}(110)$ & -4301.79 & -4488.27 & -4408.58 & -79.68 & -275.68 \\
\hline
\end{tabular}

Table 10 Outputs and desciptors calculated by the Monte Carlo simulation for adsorption of triazepine carboxylate compounds on $\mathrm{Fe}(1$ $10)$

\begin{tabular}{lllll}
\hline System & Compound $\mathrm{d} E_{\mathrm{ad}} / \mathrm{d} N_{i}$ & $\mathrm{H}_{2} \mathrm{O} \mathrm{d} E_{\mathrm{ad}} / \mathrm{d} N_{i}$ & $\mathrm{H}_{3} \mathrm{O}^{+} \mathrm{d} E_{\mathrm{ad}} / \mathrm{d} N_{i}$ & $\mathrm{Cl}^{-} \mathrm{d} E_{\text {ad }} / \mathrm{d} N_{i}$ \\
\hline $\mathrm{Cl}-\mathrm{Me}-\mathrm{CO}_{2} \mathrm{Et} / \mathrm{Fe}(110)$ & -233.78 & -13.49 & -136.96 & -74.79 \\
$\mathrm{Cl}-\mathrm{Me}-\mathrm{CN} / \mathrm{Fe}(110)$ & -275.68 & -11.59 & -147.73 & -155.31 \\
$\mathrm{Me}-\mathrm{CN} / \mathrm{Fe}(110)$ & -252.90 & -8.65 & -150.43 & -141.67 \\
\hline
\end{tabular}

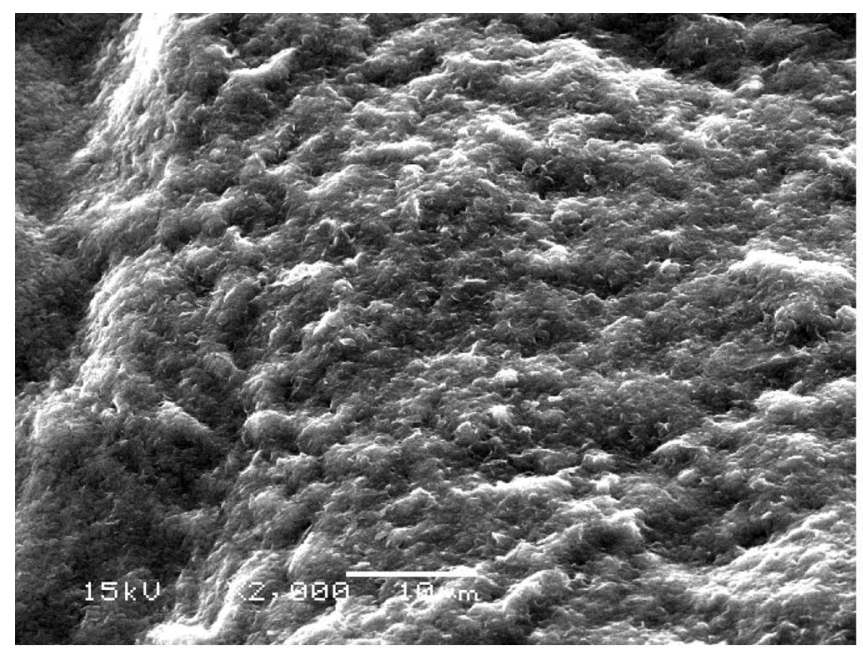

(a)

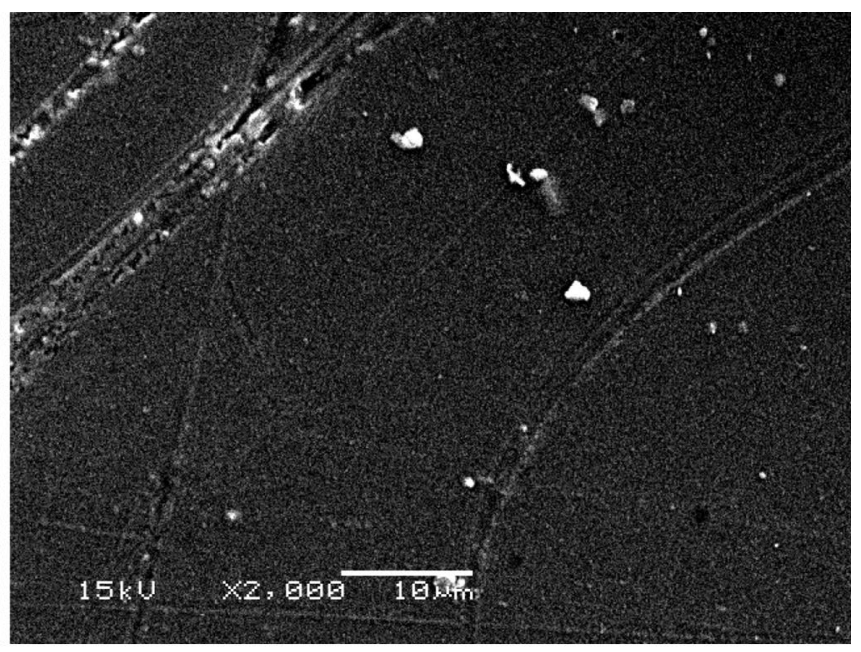

(b)

Fig. 9 Scanning electron microscopy (SEM) of mild steel after immersion for $6 \mathrm{~h}$ in $1.0 \mathrm{M} \mathrm{HCl}$ (a) without inhibitor, (b) with $10^{-3} \mathrm{M}$ of best inhibitor ( $\mathrm{Cl}-\mathrm{Me}-\mathrm{CN})$

adsorbed layer on the surface of mild steel in the acidic condition. It is found that the 3D optical profiler images of mild steel findings were in accordance with the scanning electron microscopy (SEM) analysis. Images (10-a) reveal that surface topography of uncorroded metal surface is shown. Addition of inhibitor $(\mathrm{Cl}-\mathrm{Me}-\mathrm{CN})$ on mild steel has drastically reduced the rate of corrosion as shown in Fig. 10b. Further, steel surface in the presence of the inhibitor was found to be smoother. It was also observed that the metal surface is covered with inhibitor molecules forming a film which is compact on the entire surface. Moreover, it is clear from the 3D optical profiler images that the steel surface is homogeneous compared to uninhibited simple.

The influence of the inhibitors' addition on the hydrochloric acid medium is shown in Fig. 10a. The morphology shows a rough surface, characteristic of uniform corrosion of mild steel in acid, that corrosion does not occur in presence of inhibitors and hence corrosion was inhibited strongly when the inhibitors was present in the sulfuric acid solution, and the surface layer is very rough. Also, there is an adsorbed film adsorbed on mild steel surface Fig. 10b. In accordance, it might be concluded that the adsorption film can efficiently inhibit the corrosion of mild steel.

\section{Conclusion}

All the examined substituted triazepine carboxylate compounds are effective corrosion inhibitors for mild steel in $1.0 \mathrm{M} \mathrm{HCl}$ solution. The potentiodynamic polarization curves indicated that these compounds act as mixed-type 


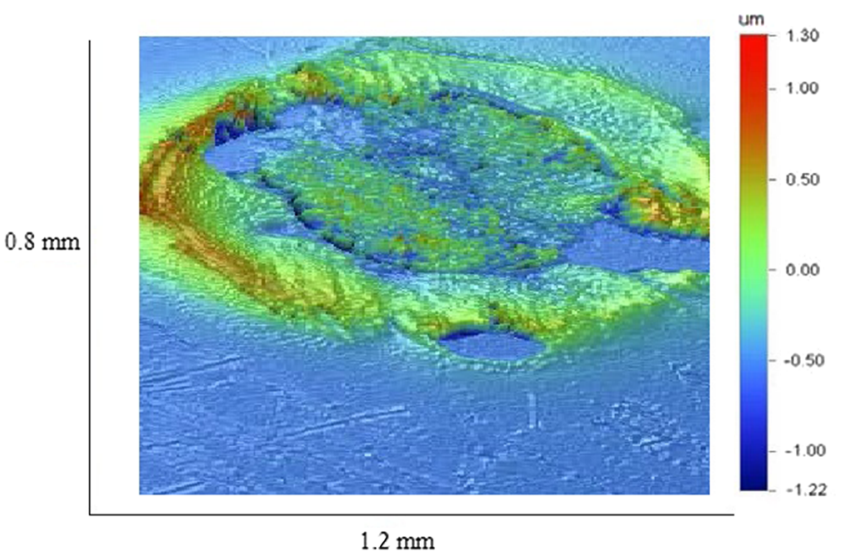

(a)

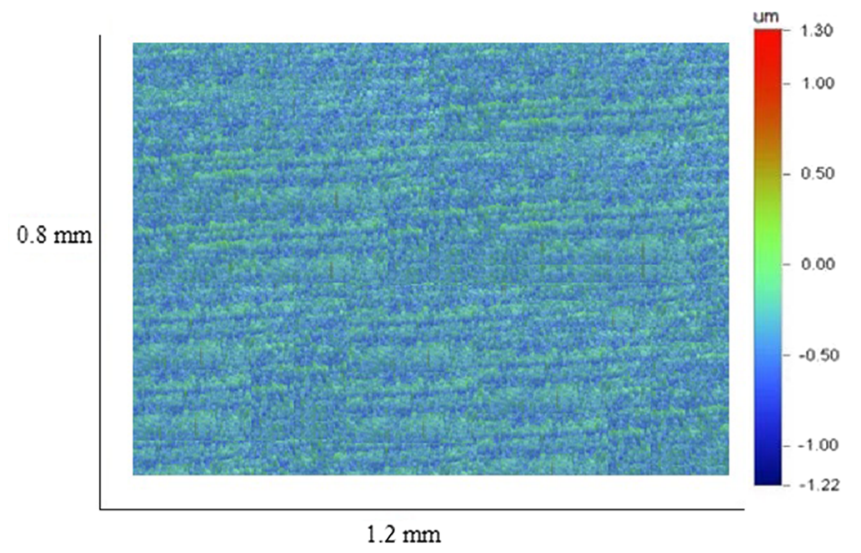

(b)

Fig. 10 Three-dimensional optical profiler images of mild steel immersed for $6 \mathrm{~h}$ in $1.0 \mathrm{M} \mathrm{HCl}$ (a) without inhibitor, (b) with $10^{-3} \mathrm{M}$ of $\mathrm{Cl}-\mathrm{Me}-$ $\mathrm{CN}$

inhibitors and their inhibition efficiencies increase with their concentrations to reach a maximum at $10^{-3} \mathrm{M}$. It is also found that the mechanism of the hydrogen reduction and the iron dissolution reactions change by the inhibitors' addition. They act by adsorption mechanism at the metallic surface and their inhibition depended on the nature of the $(-\mathrm{C} \equiv \mathrm{N})$ cyano group presented in their structures and the $\mathrm{Cl}-\mathrm{Me}-\mathrm{CN}$ compound is the best inhibitor. So, it is found also that the order of the inhibition efficiencies of the studied compounds was confirmed by all techniques' measurements. When the inhibitor was present in the solution, then scanning electron microscopy (SEM) and 3D optical profiler images observation confirmed the existence of an absorbed protective film on the mild steel surface.

Open Access This article is licensed under a Creative Commons Attribution 4.0 International License, which permits use, sharing, adaptation, distribution and reproduction in any medium or format, as long as you give appropriate credit to the original author(s) and the source, provide a link to the Creative Commons licence, and indicate if changes were made. The images or other third party material in this article are included in the article's Creative Commons licence, unless indicated otherwise in a credit line to the material. If material is not included in the article's Creative Commons licence and your intended use is not permitted by statutory regulation or exceeds the permitted use, you will need to obtain permission directly from the copyright holder. To view a copy of this licence, visit http://creativecommons.org/licenses/by/4.0/.

\section{References}

1. El Kacimi Y et al (2016) Effect of silicon and phosphorus contents in steel on its corrosion inhibition in $5 \mathrm{M} \mathrm{HCl}$ solution in the presence of cetyltrimethylammonium/KI. J Mater Environ Sci 7(1):371-381

2. Ebenso EE (2001) Inhibition of corrosion of mild steel hydrochloric acid by some azo dyes. Niger J Chem Res 6(1):8-12
3. Elkacimi $\mathrm{Y}$ et al (2012) Inhibition of mild steel corrosion by some phenyltetrazole substituted compounds in hydrochloric Acid. Port Electrochim Acta 30(1):53-65. https://doi.org/10.4152/pea.20120 1053

4. El Kacimi Y et al (2017) Corrosion inhibition studies for mild steel in $5.0 \mathrm{M} \mathrm{HCl}$ by substituted phenyltetrazole. Euro Mediterr J Environ Integr 2(1):1-11. https://doi.org/10.1007/s4120 7-016-0011-8

5. Noor EA, Al-Moubaraki AH (2008) Corrosion behavior of mild steel in hydrochloric acid solutions. Int J Electrochem Sci 3:806-818

6. Thomas JGN (1981) 5th European symposium on corrosion inhibitors 1980, Ann. Univ. Ferrara, Italy

7. Galai $\mathrm{M}$ et al (2017) Characterization and anti-corrosion properties of novel quinolinol on C-steel in a molar hydrochloric acid solution. Port Electrochim Acta 35(4):233-251. https://doi. org/10.4152/pea.201704233

8. Elattar K-M et al (2016) Advances in 1,3,5-triazepines chemistry. RSC Adv 6:37286-37307

9. Elattar K-M et al (2015) Advances in 1,2,4-triazepines chemistry. RSC Adv 5:106710-106753. https://doi.org/10.1039/C5RA2 $1108 \mathrm{E}$

10. Serrar $\mathrm{H}$ et al (2017) Synthesis and evaluation of novel pyrido[1,2b] $[1,2,4]$ triazine-2,6-dione and pyrido[1,2-b][1,2,4]triazepine2,7-dione derivatives as antioxidant agents. Lett Org Chem $14: 267-277$

11. ASTM Practice Standard G-31, Standard Practice for Laboratory Immersion Corrosion Testing of Metals. West Conshohocken: ASTM International (2004)

12. Galai M et al (2017) Synthesis, characterization and anti-corrosion properties of novel quinolinol on $\mathrm{C}$-steel in a molar hydrochloric acid solution. Port Electroch Acta 35:233

13. Stern M, Geary A-L (1957) Electrochemical polarization I. A theoretical analysis of the shape of polarization curves. J Electrochem Soc 104:56-63

14. Obot I-B, Obi-Egbedi N-O (2010) Acenaphtho [1,2-b] quinoxaline as a novel corrosion inhibitor for mild steel in $0.5 \mathrm{M} \mathrm{H} 2 \mathrm{SO} 4$. Corros Sci 52:923-926

15. Salarvand $\mathrm{Z}$ et al (2017) Enhanced corrosion resistance of mild steel in $1 \mathrm{M} \mathrm{HCl}$ solution by trace amount of 2-phenyl-benzothiazole derivatives: experimental, quantum chemical calculations and molecular dynamics simulation studies. Corros Sci 114:133-145 
16. Obot I-B et al (2013) Experimental, quantum chemical calculations, and molecular dynamic simulations insight into the corrosion inhibition properties of 2-(6-methylpyridin-2-yl) oxazolo $[5,4-\mathrm{f}][1,10]$ phenanthroline on mild steel. Res Chem Intermed 39:1927-1948

17. Fouda A-S et al (2017) Evaluation of 4-amidinophenyl-2,2'bithiophene and its aza-analogue as novel corrosion inhibitors for CS in acidic media: experimental and theoretical study. J Mol Liq 240:372-388. https://doi.org/10.1016/j.molliq.2017.05.089

18. Fouda A-S et al (2017) Experimental and theoretical studies on corrosion inhibition of 4-amidinophenyl-2,2'-bifuran and its analogues in acidic media. RSC Adv 7:46414-46430. https://doi. org/10.1039/c7ra08092a

19. Sun $\mathrm{H}$ et al (1998) The COMPASS force field: parameterization and validation for phosphazenes. Comput Theor Polym Sci $8: 229-246$

20. Chermette H (1999) Chemical reactivity indexes in density functional theory. J Comp Chem 20:129-154

21. Parr R-G, Chattaraj P-K (1991) Principle of maximum hardness. J Am Chem Soc 113:1854-1855

22. Iczkowski VRP (1961) Electronegativity. J Am Chem Soc 83:3547-3551

23. Koopmans T (1993) Über die Zuordnung von Wellenfunktionen und Eigenwerten zu den Einzelnen Elektronen Eines Atoms. Physica 1:104-113

24. Yang W et al (1985) Molecular softness as the average of atomic softnesses: companion principle to the geometric mean principle for electronegativity equalization. J Phys Chem 89:5412-5414

25. Yang W, Parr RG (1985) Hardness, softness, and the Fukui function in the electronic theory of metals and catalysis. Proc Natl Acad Sci 82:6723-6726

26. Chattaraj P-K (2006) Electrophilicity index. Chem Rev 106:2065-2091

27. Ateya B-G et al (1976) Thiosemicarbazide as an inhibitor for acid corrosion of iron. Corros Sci 16:163-169

28. Alaoui K et al (2016) Anti-corrosive properties of polyvinylalcohol for carbon steel in hydrochloric acid media: electrochemical and thermodynamic investigation. J Mater Environ Sci 7:2389-2403

29. Alaoui K et al (2018) Electrochemical and computational studies of some triazepine carboxylate compounds as acid corrosion inhibitors for mild steel. J Bio Tribo Corros 4(37):1-18

30. Abboud $Y$ et al (2007) Corrosion inhibition of carbon steel in acidic media by bifurcaria bifurcata extract. Mater Chem Phys 105:1-5

31. Bentiss $F$ et al (2009) Corrosion control of mild steel using 3,5-bis(4-methoxyphenyl)-4-amino-1,2,4-triazole in normal hydrochloric acid medium. Corros Sci 51:1628-1635

32. Hassan $\mathrm{H}-\mathrm{H}$ et al (2007) Inhibition of mild steel corrosion in hydrochloric acid solution by triazole derivatives: part I. Polarization and EIS studies. Electrochim Acta 52:6359-6366

33. Aksüt A-A et al (1982) The determination of corrosion rates by electrochemical d.c. and a.c. methods-II. Systems with discontinuous steady state polarization behavior. Corros Sci 22:611-619

34. Trethewey K-R et al (1995) Corrosion for science and engineering. In: 2nd edition, Edinburgh Gate Harlow, Essex CM20 2JE, England

35. Behpour M et al (2008) Electrochemical and theoretical investigation on the corrosion inhibition of mild steel by thiosalicylaldehyde derivatives in hydrochloric acid solution. Corros Sci $50: 2172-2181$

36. Solmaz R (2010) Investigation of the inhibition effect of 5-((E)4-phenylbuta-1,3-dienylideneamino)-1,3,4-thiadiazole-2-thiol Schiff base on mild steel corrosion in hydrochloric acid. Corros Sci 52:3321-3330
37. Rbaa M et al (2019) electrochemical and theoretical evaluation of some quinoline derivatives as corrosion inhibitors of mild steel in acidic medium. Anal Bioanal Electrochem 11(7):969-984

38. Lopez DA et al (2003) The influence of steel microstructure on $\mathrm{CO}_{2}$ corrosion. EIS studies on the inhibition efficiency of benzimidazole. Electrochim Acta 48:845-854

39. El Kacimi Y et al (2018) Surface morphology studies and kineticthermodynamic characterization of steels treated in $5.0 \mathrm{M} \mathrm{HCl}$ medium: hot-dip galvanizing application. Anti-Corros Methods Mater 65:176-189

40. Zheng X et al (2014) Investigation of 1-butyl-3-methyl-1H-benzimidazolium iodide as inhibitor for mild steel in sulfuric acid solution. Corros Sci 80:383-392

41. Bentiss $F$ et al (2012) Improvement of corrosion resistance of carbon steel in hydrochloric acid medium by 3,6-bis(3-pyridyl) pyridazine. Int J Electrochem Sci 7:1699-1723

42. Alaoui K et al (2016) Poly (1-phenylethene): as a novel corrosion inhibitor for carbon steel/hydrochloric acid interface. Anal Bioanal Electrochem 8:830-847

43. Hassan $\mathrm{H}-\mathrm{H}$ (2006) Perchlorate and oxygen reduction during $\mathrm{Zn}$ corrosion in a neutral medium. Electrochim Acta 51:5966-5972

44. Kaya S, Kaya C (2015) A new equation for calculation of. chemical hardness of groups and molecules. Mol Phys 113:1311-1319

45. Kaya S, Kaya C (2015) A new method for calculation of molecular hardness: a theoretical study. Theor Chem 1060:66-70

46. Pearson R-G (1987) Chemical hardness and bond dissociation energies. J Chem Edu 64:561-567

47. Kaya $\mathrm{S}$ et al (2016) Determination of corrosion inhibition effects of amino acids: Quantum chemical and molecular dynamic simulation study. J Taiwan Inst Chem Eng 58:528-535

48. Obot IB, Gasem ZM (2014) Theoretical evaluation of corrosion inhibition performance of some pyrazine derivatives. Corros Sci 83:359-366

49. Rapaport D-C (1996) The art of molecular dynamics simulation. Comput Phys 10:456

50. Van Gunsteren W-F, Berendsen H-J (1990) Computer simulation of molecular dynamics: methodology, applications, and perspectives in chemistry. Angew Chem Int Ed 29:992-1023

51. Alaoui K et al (2019) Molecular dynamics, monte-carlo simulations and atomic force microscopy to study the interfacial adsorption behaviour of some triazepine carboxylate compounds as corrosion inhibitors in acid medium. J Bio Tribo Corros 5(1):1-16

52. Durnie W et al (1999) Development of a structure-activity relationship for oil field corrosion inhibitors. J Electrochem Soc 146:1751-1756

53. ElBelghiti M (2016) Experimental, quantum chemical and Monte Carlo simulation studies of 3, 5-disubstituted-4-amino-1, 2, 4-triazoles as corrosion inhibitors on mild steel in acidic medium. J Mol Liq 218:281-293

54. Saha S-K (2016) A comparative density functional theory and molecular dynamics simulation studies of the corrosion inhibitory action of two novel $\mathrm{N}$-heterocyclic organic compounds along with a few others over steel surface. J Mol Liq 215:486-495

55. Singh A-K, Quraishi M-A (2010) The effect of some bis-thiadiazole derivatives on the corrosion of mild steel in hydrochloric acid. Corros Sci 52:1373-1385

Publisher's Note Springer Nature remains neutral with regard to jurisdictional claims in published maps and institutional affiliations. 